Çukurova Üniversitesi Mühendislik Mimarlık Fakültesi Dergisi, 30(2), 25-40 ss., Aralık 2015

Çukurova University Journal of the Faculty of Engineering and Architecture, 30(2), pp. 25-40, December 2015

\title{
Isıtma Tesisatında Kullanılan Plastik Borular için Sürtünme Basınç Kaybı Gradyanı Çizelgesinin Hazırlanması ve Örnek Projeye Uygulanması
}

\author{
Mehmet Tahir ERDINÇ⿻1, Alper YILMAZ ${ }^{* 2}$ \\ Tuncay YILMAZ ${ }^{1}$ \\ ${ }^{\text {I} O s m a n i y e ~ K o r k u t ~ A t a ~ U ̈ n i v e r s i t e s i, ~ M u ̈ h . ~ F a k u ̈ l t e s i, ~ M a k i n e ~ M u ̈ h e n d i s l i g ̆ i ~ B o ̈ l u ̈ m u ̈, ~ O s m a n i y e, ~}$ \\ ${ }^{2}$ Çukurova Üniversitesi, Mühendislik-Mimarlık Fakültesi, Otomotiv Müh. Bölümü, Adana
}

Geliş tarihi: 09.10.2015 Kabul tarihi:10.11.2015

\section{Özet}

Isıtma sistemlerinde son yıllarda plastik borular hafif ve korozyona karşı dirençli olduğundan dolayı tercih edilmeye başlamıştır. Isıtma tesisatında kullanılacak pompanın seçimi için bilindiği üzere kazan çıkışındaki su debisi yanında kritik devrenin toplam basınç kaybının da bulunması gerekmektedir. Çelik borular için sıcaklık farkı $(\Delta \mathrm{T}) \Delta \mathrm{T}=1^{\circ} \mathrm{C}$ ve $\Delta \mathrm{T}=20^{\circ} \mathrm{C}$ için sürtünme basınç kaybı gradyanı (SBKG) $\mathrm{R}$ $(\mathrm{Pa} / \mathrm{m})$ çizelgesi bulunmaktadır. Bu çalışmada ise plastik borular için standartlarda verilen boru çapları kullanılarak $\Delta \mathrm{T}=10^{\circ} \mathrm{C}$ için sürtünme basınç kaybı gradyanı çizelgesi çıkartılmış olup, örnek bir tesisatta hem çelik boru hem de plastik boru kullanılması durumundaki basınç kaybı değerleri karşılaştırılmıştır.

Anahtar kelimeler: Isıtma, Plastik boru, Sürtünme basınç kaybı gradyanı

\section{Determination of Chart for Friction Pressure Drop Gradient for Heating System Using Plastic Pipes with Application to a Sample Project}

\begin{abstract}
In last years, plastic pipes are most preferred because they are light and resistant to corrosion. To select pump of the heating system; beside the water flow rate after the boiler, the total pressure drop in the critical cycle of the system must be known. For $\Delta \mathrm{T}=1^{\circ} \mathrm{C}$ and $\Delta \mathrm{T}=20^{\circ} \mathrm{C}$ steel pipe friction pressure drop gradients $\mathrm{R}(\mathrm{Pa} / \mathrm{m})$ are given in literature. In this study, for plastic pipes of different diameters, friction pressure drop gradients are determined for $\Delta \mathrm{T}=10^{\circ} \mathrm{C}$ and a case study for steel and plastic pipe application is carried out and result are compared.
\end{abstract}

Keywords: Heating, Plastic pipe, Friction pressure drop gradient.

\footnotetext{
*Yazışmaların yapılacağı yazar: Alper YILMAZ, Çukurova Üniversitesi, Mühendislik-Mimarlık Fakültesi, Otomotiv Mühendisliği Bölümü,01330 Adana, alpyil@cu.edu.tr
} 


\section{GİRIŞ}

Isıtma ihtiyacının yanında artık konfor ve enerji tasarrufu da önem kazanmaktadır. Buna bağlı olarak binalarda 1sitma sistemlerinde, daha iyi yalıtım malzemelerinin kullanılması, oda termostatlarının konulması, daha verimli kazanların ve değişken devirli pompaların kullanılması gibi yenilikler var olmaya başlamış ve buna bağlı olarak da bu konudaki standartlar ve kurallar da hızlı değişime uğramaktadır. Diğer önemli yenilikler ise pompalı 1sitma sistemlerinde plastik boruların ve isı pay ölçerlerin (1sı sayacı) kullanımıdır. Plastik boruların hafif ve korozyona karşı dirençli olması kullanımını bazı durumlarda cazip hale getirmektedir. Plastik borular hali hazırda sihhi tesisatta yaygin olarak kullanılmaktadır. Özellikle plastik teknolojisindeki gelişmeler sayesinde yüksek sıcaklıklara dayanıklı boruların üretilmesiyle bu boruların pompalı 1sıtma tesisatlarında kullanımına olanak sağlanmıştır.

Diğer önemli bir yenilik ise 1sı pay ölçerlerin 1sıtma tesisatlarında kullanımıdır. Isı pay ölçer üzerine yerleştirildiği 1sıtma hattından geçen 1S1 enerjisi miktarını debi ve sıcaklık farkına göre ölçen cihazdır. Is1 pay ölçerlerin kullanımı Bayındırlık ve İskan Bakanlığı tarafindan hazırlanan 14.04.2008 tarih ve 26847 sayılı Resmi Gazete' de yayımlanan "Merkezi Isıtma ve Sihhi Sicak Su Sistemlerinde Isınma ve Sihhi Sicak Su Giderlerinin Paylaştırılmasına İlişskin Yönetmelik" ile yürürlüğe girmiştir [1].

\section{2. ÖNCEKİ ÇALIȘMALAR}

Isıtma sistemleri hesapları için hem 1sı transferi hem de akışkanlar mekaniği bilgisi gerektirmektedir. Isıtma tesisatının pompa hesabı için kritik devrenin basınç kaybının bulunması gerekmektedir. Basınç kaybı sürtünmeden dolayı oluşan kayıplar ve yerel kayıplar olarak ikiye ayrılır. Sürtünmeden dolayı oluşan basınç kaybı türbülanslı akışta Reynolds sayısı yanında pürüzlülük katsayısının yani boru malzemesinin de fonksiyonudur. Bundan dolayı kullanılacak boru malzemesinin önemi vardır. Boru boyutlandırmasının amacı en iyi ve en ekonomik şekilde tesisatın yapılmasıdır [2]. Literatürde, çelik borular için $\Delta \mathrm{T}=1^{\circ} \mathrm{C}$ ve $\Delta \mathrm{T}=20^{\circ} \mathrm{C}$ için sürtünme basınç kaybı gradyanı $(\mathrm{SBKG}) \mathrm{R}(\mathrm{Pa} / \mathrm{m})$ çizelgesi standartlarda belirtilen çaplara göre 1sitma yükünün fonksiyonu olarak verilmektedir [3]. Isıtma tesisatlarında kritik devre seçimi ve boru çapı tayini ile ilgili detaylı bilgiler çelik ve bakır borular için basınç kaybı grafikleri Isısan [4] çalışmasında verilmiştir. Akar [5] yaptığı çalışmada plastik boruların gerekliliği ve özellikleri hakkında bilgi vermiştir. Çakmanus ve İman [6]' in çalışmasında ve Ashrae [7]'de plastik boru çeşitleri ve her birinin özellikleri ile ilgili ayrıntılı bilgi bulunmaktadır. Bulgurcu ve Özmen [8] yaptıkları bir çalışmada plastik boru ile çelik borudaki basınç kayıplarını deneysel olarak karşılaştırmışlardır. Zgoul ve Habali [9] yaptıkları çalışmada enerji verimliliği bakımından plastik boruların çelik borulardan daha iyi olduğunu belirtmişlerdir. Ashrae [10] de plastik borular için basınç kaybı gradyanı bir grafikle debinin fonksiyonu olarak verilmiştir. Yapılan literatür çalışmasında ısıtma tesisatında kullanılan plastik borular için SBKG'nin ısıtma yüküne bağlı olarak çizelgeler bulunmamaktadır.

$\mathrm{Bu}$ çalışmada sıcak sulu 1sıtma sistemi için $\Delta \mathrm{T}=10^{\circ} \mathrm{C} \quad$ sicaklık farkı durumunda plastik borular için belirtilen çizelgeler verilmiştir. $\Delta \mathrm{T}=10^{\circ} \mathrm{C}$ verilmesinin nedeni doğal gaz yakıtlı yoğuşmalı kazan kullanımının yaygınlaşmasıdır. Ayrıca örnek bir tesisat için çelik boru ile plastik boru kullanılarak basınç kayıpları karşılaştırılmıştır. Hesaplamalara 1sı pay ölçer basınç kaybı da dahil edilmiştir.

\section{BORU ÇAPI HESABI}

Boru çaplarının belirlenmesi için boruların kat planlarında ve kolon şemalarında belirtilmesi ve 1sıtma sisteminde kullanılacak çeşitli armatür ile bağlantı yer ve şekillerinin belirtildiği bir kolon şemasının çizilmiş olması gereklidir. Kolon şemasında kazan, pompa ile vanalar ve sistemde 
kullanılan kapalı genleşme kabı da belirtilir. Boru çap1 hesapları için ilk önce kritik devrenin belirlenmesi gereklidir. Kritik devre basınç kaybının en yüksek olacağı devre olarak tanımlanır. Bu tanıma göre normal olarak yapılan pompalı 1sitma sistemlerinde kazandan en uzak ve 1S1 yükü en fazla olan devre kritik devre olarak adlandırılır. Eğer en uzak devre en yüksek 1sı yükü taşımıyorsa, o zaman $A=\dot{Q}^{2} . L$ değeri yüksek olan devre kritik devre olarak belirlenebilir. Burada $\dot{Q}$ 1s1 yükü ve L boru uzunluğudur. Buna rağmen seçilen devrenin kritik devre olmadığı diğer devrelerin hesaplanması sırasında anlaşıldığında, kritik devreyi önce yanlış tahmin etmenin fazladan hesap yapmış olmak dışında bir zararı olmaz.

Çapların belirlenmesinde çeşitli yöntemler vardır. Bunlardan en önemlileri hiz metodu ve sabit sürtünme basınç gradyanı metodudur. Hız metodu basit bir metot olup, hesaplar kolaydır. Ancak sistemde basınç dengeleri gözetilmediği için istenen debilerin istenen 1sitıcılara gitmesi mümkün değildir. $\mathrm{Bu}$ durum ancak kolonlara konulacak kolon ayar vanaları ile zahmetli bir işle ayarlanabilir. Sabit sürtünme basınç gradyanı metodunda ise belirli bir basınç gradyanında en ekonomik boru çapının seçileceği durum dikkate alınır. Şekil 1'de ilk yatırım ve işletme giderlerinin boru çapından bağımlılığı şematik olarak gösterilmiştir.

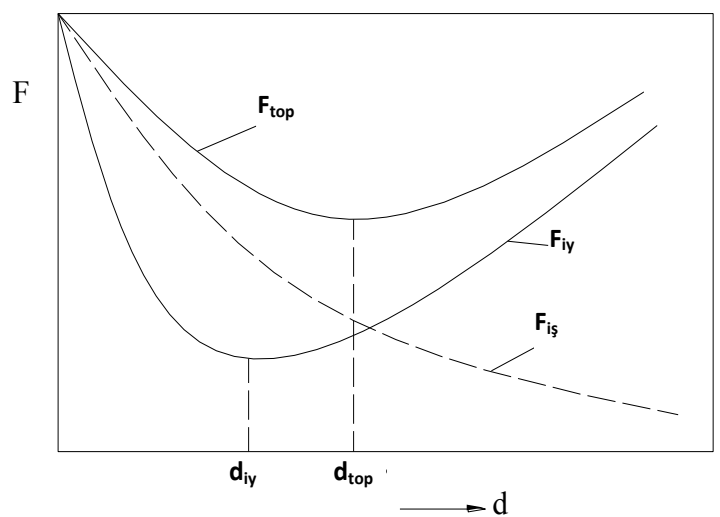

Şekil 1. İlk yatırım, işletme ve toplam fiyatların boru çapı ile değişimi
İlk yatırım fiyatları $\left(\mathrm{F}_{\mathrm{iy}}\right)$ boru çapı büyüdükçe artmaktadır. Boru çapı sıfıra gittiğinde de ilk yatırım masrafları, pompa sistemi çok büyüdüğünden, yine artacaktır. Bundan dolay1 sadece ilk yatırım masrafları dahi düşünülse ekonomik bir optimum $\mathrm{d}_{\text {iy }}$ boru çap1 vardır. İşletme masrafları $\left(\mathrm{F}_{\mathrm{iy}}\right)$ boru çapı ile azalmaktadır, çünkü bilhassa pompanın harcadığı güç azalmaktadır. Bundan dolayı toplam masraflar bir $\mathrm{d}_{\text {top }}$ boru çapında en küçük olacaktır. Gayet tabiidir ki, $d_{\text {top }}$ değeri $\mathrm{d}_{\text {iy }}$ değerinden daha büyüktür.

Yapılan sistemlerde edinilen deneylere göre ekonomik çap, belirli bir sürtünme basınç gradyanı için belirlenebilmekte ve bu değer genelde $\mathrm{R}=50$ $400 \mathrm{~Pa} / \mathrm{m}$ olarak kabul edilebilmektedir. Enerji maliyetinin yüksek olduğu ülkelerde $\mathrm{R}$ küçük, düşük olduğu ülkelerde de $\mathrm{R}$ büyük seçilir. Ülkemizde daha çok $\mathrm{R}=100 \mathrm{~Pa} / \mathrm{m}$ seçilmektedir.

\section{SBKG BULUNMASI \\ ÇIZELGESININ}

Borudan geçen 1Sı miktarı Eşt.(1) ilehesaplanabilir:

$\dot{\mathrm{Q}}=\dot{\mathrm{M}} \mathrm{c}_{\mathrm{P}} \Delta \mathrm{T}$

Burada $\dot{\mathrm{M}}, \mathrm{c}_{\mathrm{P}}$ ve $\Delta \mathrm{T}$ sırasıyla suyun kütlesel debisi, özgül ısısı ve kazan giriş-çıkış sıcaklık farkıdır. Suyun kütlesel debisi ise

$\dot{\mathrm{M}}=\rho u \mathrm{~A}_{\mathrm{i}}$

şeklinde yazılarak,

$\dot{\mathrm{Q}}=\rho \mathrm{A}_{\mathrm{i}} \mathrm{c}_{\mathrm{P}} \Delta \mathrm{T}$

elde edilir. Burada boru kesit alanı $\mathrm{A}_{\mathrm{i}}$ ' de

$\mathrm{A}_{\mathrm{i}}=\frac{\pi * \mathrm{~d}^{2}}{4}$

şeklinde bulunur. Bir metre borudaki sürtünmeden dolayı oluşan SBKG R(Pa/m); 
Isıtma Tesisatında Kullanılan Plastik Borular için Sürtünme Basınç Kaybı Gradyanı Çizelgesinin Hazırlanması ve Örnek Projeye Uygulanmast

$\mathrm{R}=\frac{\Delta \mathrm{P}}{\mathrm{L}}$

şeklinde tarif edilir ve

$R=\frac{f \rho u^{2}}{2 d}$

eşitliği ile hesaplanır. $\rho, \mathrm{u}, \mathrm{d}$ ve L sırasıyla suyun yoğunluğu, su hızı, boru iç çap1 ve boru uzunluğudur. Sürtünme katsayısı f ise Eşt.(7)' de verilen Colebrook denklemi [11] ile hesaplanır.

$\frac{1}{\sqrt{\mathrm{f}}}=-2 * \log 10\left(\frac{\varepsilon / \mathrm{d}}{3,7}+\frac{2,51}{\operatorname{Re} \sqrt{\mathrm{f}}}\right)$

Burada $\varepsilon$, Re mutlak pürüzlülük ve Reynolds sayısıdır. Re sayısı da

$\operatorname{Re}=\frac{\mathrm{ud}}{\mathrm{v}}$

bağıntısıyla belirlenir. $v$ suyun kinematik viskositesidir.

Normal hesaplarda verilen bir $\mathrm{R}$ ve $\dot{\mathrm{Q}}$ değerlerinde gerekli boru çapı Eşt.(3)-(6) kullanılarak

$\mathrm{d}=\left(\frac{8 \mathrm{f}}{\rho \pi^{2} R}\right)^{1 / 5}\left(\frac{\dot{\mathrm{Q}}}{c_{P} \Delta T}\right)^{2 / 5}$

şeklinde hesaplanır. Burada f iterasyonla Eşt.(7) den bulunur. İmal edilen borular için verilen çizelgelerden de hesaplanan çapa en uygun boru çapı belirlenir. Sonra da bu verilen borunun çap1 ve pürüzlülüğü esas alınarak gerçek SBKG aşağıdaki eşitlikten belirlenir.

$\mathrm{R}=\frac{8 \mathrm{f}}{\rho \pi^{2}}\left(\frac{\dot{\mathrm{Q}}}{c_{P} \Delta T}\right)^{2} \frac{1}{d^{5}}$
$\mathrm{Bu}$ çalışmada çizelgelerin belirlenmesinde, önce imal edilen bir boru çap1 ve borunun pürüzlülüğü verilerek $\dot{Q}$ ve u, SBKG R' nin fonksiyonu olarak bulunacaktır:

$\dot{\mathrm{Q}}=c_{P} \Delta T\left(\frac{\rho \pi^{2} d^{5} R}{8 f}\right)^{1 / 2}$

$\mathrm{Bu}$ değerle de Eşitlik (3)'ten akış hızı u hesaplanacaktır.

Çizelge hesabında $\Delta \mathrm{T}=10^{\circ} \mathrm{C}$ alınmıştır. Çizelgede hı u ve 1sı yükünü $\dot{Q}$ doğrudan hesaplanamadığı için bir programlama dili kullanılarak nümerik olarak hesaplanmıştır. Programın akış şeması Şekil 2 de verilmiştir.

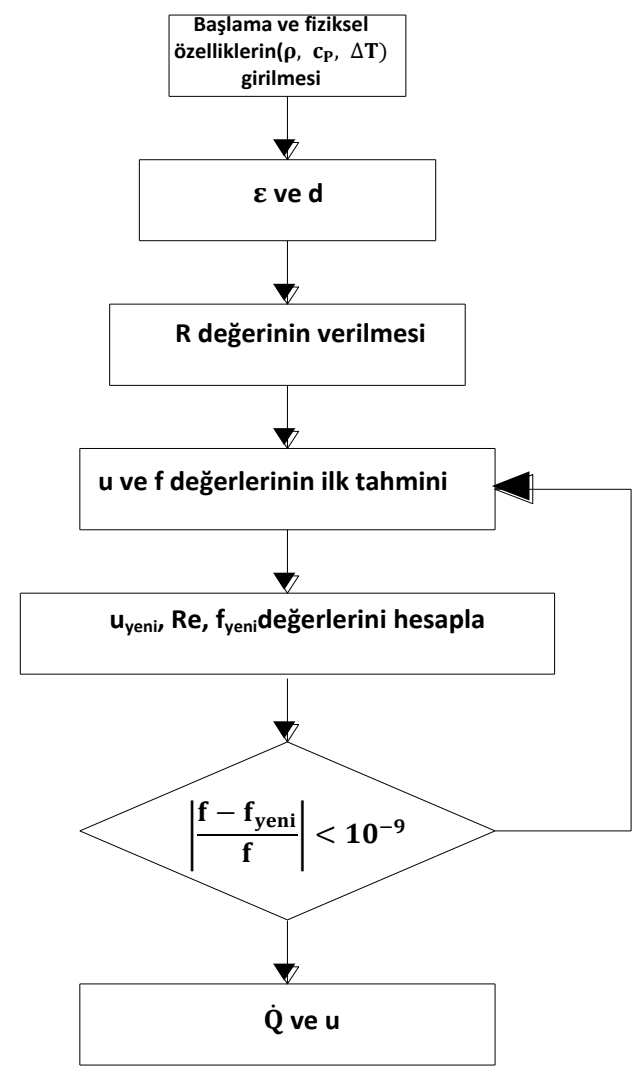

Şekil 2. Program akış şeması 


\section{5. ÇIZZLLGE ÖRNEKLERI}

Plastik borularda $\Delta \mathrm{T}=10^{\circ} \mathrm{C}$ için SBKG Çizelge 1' de verilmiştir. Boru çapları için DIN 8077 de verilen değerler esas alınmıştır. Çelik borularda $\Delta \mathrm{T}=10^{\circ} \mathrm{C}$ için SBKG ise Çizelge 2' de verilmiştir. Diğer sıcaklık farkları $\Delta \mathrm{T}_{d}$ için $\dot{\mathrm{Q}}$ değeri olarak sanal bir $\dot{Q}_{s}$ değeri aşağıdaki gibi seçilmelidir.

$\dot{\mathrm{Q}}_{s}=\dot{\mathrm{Q}} \frac{\Delta T}{\Delta \mathrm{T}_{d}}$

$\mathrm{Bu}$ değerler ile verilen çizelgeler aynen kullanılabilir.

\section{6. ÖRNEK HESAPLAMALARI}

TESISAT

Örnek tesisat kolon şeması ve daire kat planı Şekil 3' te gösterilmiştir. Burada yönetmelik dikkate alınarak pay ölçerli sistem seçilmiștir. Bu sistem hem plastik hem de çelik borular için hesaplanacaktır. Hesaplarda sürtünme basınç gradyanının yaklaşık $\mathrm{R}=100 \mathrm{~Pa} / \mathrm{m}$ civarında ve hızların da kazan çıkışında $0,8 \mathrm{~m} / \mathrm{s}^{\prime}$ den, daire içerisinde $0,5 \mathrm{~m} / \mathrm{s}$ 'den büyük olmamaları dikkate alınmıştır.

\subsection{Plastik Boru için Hesaplamalar}

Yerel basınç kayıp katsayısı $\zeta$ değerleri çizelgesi Çizelge 2' de, boru hesabı cetveli Çizelge 3' te ve 1sı pay ölçer basınç kaybı grafiği Şekil 4' te verilmiştir. Bir j borusundaki basınç kaybı

$\Delta \mathrm{P}_{\mathrm{j}}=\mathrm{L}_{j} * \mathrm{R}_{j}+\left(\sum_{i} \zeta_{i}\left(\frac{\rho \mathrm{u}^{2}}{2}\right)_{i}\right)_{j}$

olarak hesaplanır.

Çizelge 4' ten görüleceği gibi

$\Delta \mathrm{P}_{\mathrm{T}}=19029 \mathrm{~Pa}$ olarak bulunur. $\mathrm{j}$ boru numarasını ve $\mathrm{i}$ de $\mathrm{j}$ borusundaki yerel kayıları göstermektedir. $\Delta \mathrm{P}_{\mathrm{T}}$ ise toplam basınç kaybıdır.

$8 / 17$ de Is1 sayac1 DN 20, $\dot{V}_{\mathrm{n}}=2,5 \mathrm{~m}^{3} / \mathrm{h}$ seçilmiştir. $\Delta \mathrm{T}=10^{\circ} \mathrm{C}$ fark ve

$\dot{\mathrm{M}}_{8 / 17}=\frac{17 \mathrm{~kW}}{4,182 * 10}=0,4 \frac{\mathrm{kg}}{\mathrm{s}}=1461 \mathrm{~kg} / \mathrm{h}$

$\dot{\mathrm{V}}_{8 / 17}=1,48 \mathrm{~m}^{3} / \mathrm{h}$

değeriyle 1sı sayıcındaki basınç kaybı $\left(\Delta \mathrm{P}_{\mathrm{IS}}\right)$,

$\Delta \mathrm{P}_{\mathrm{IS}}=8600 \mathrm{~Pa}$

olarak okunur.

Toplam basınç kaybı $\left(\Delta \mathrm{P}_{\mathrm{T}}\right)$

$\Delta \mathrm{P}_{\mathrm{T}}=19029+8600=27629 \mathrm{~Pa}$

$\Delta \mathrm{P}_{\mathrm{T}}=2,85 \mathrm{mSS}$

ve kazan su debisi

$\dot{\mathrm{V}}=\frac{\dot{\mathrm{Q}}}{\rho * \mathrm{c}_{\mathrm{p}} * \Delta \mathrm{T}}=\frac{238 \mathrm{~kW}}{985\left(\frac{\mathrm{kg}}{\mathrm{m}^{3}}\right) * 4,182\left(\frac{\mathrm{kJ}}{\mathrm{kg}^{\circ} \mathrm{C}}\right) * 10\left({ }^{\circ} \mathrm{C}\right)}$

$\dot{\mathrm{V}}=5,77 * 10^{-3} \frac{\mathrm{m}^{3}}{\mathrm{~s}}=20,79 \frac{\mathrm{m}^{3}}{\mathrm{~h}}$

olarak hesaplanır ve bu değerlerle pompa seçilir. Pompa seçilirken firmaların pompa karakteristik eğrileri ile pompa verim eğrileri dikkate alınır.

\section{2. Çelik Boru için Hesaplamalar}

Çelik borular için $\zeta$ değerleri Çizelge 4'te, boru hesabı cetveli Çizelge 5'te ve isı pay ölçer basınç kaybı grafiği Şekil 4' te verilmiştir. Toplam boru basınç kaybı Eşitlik (11) ile Çizelge 6'dan da görüleceği gibi;

$\Delta \mathrm{P}_{\mathrm{T}}=22632 \mathrm{~Pa}$ olarak bulunur.

Isı pay ölçer basınç kaybı plastik boru hesabı ile aynıdır. Buradan,

$\Delta \mathrm{P}_{\mathrm{T}}=22632+8600=31232 \mathrm{~Pa}$

$\Delta P_{T}=3,19 \mathrm{mSS}$ 
Isıtma Tesisatında Kullanılan Plastik Borular için Sürtünme Basınç Kaybı Gradyanı Çizelgesinin Hazırlanması ve Örnek Projeye Uygulanmast

Çizelge 1. Plastik borularda $\Delta \mathrm{T}=10^{\circ} \mathrm{C}$ için pompalı tesisatta $\mathrm{SBKG}$ R çizelgesi (Boru standartı: DIN 8077)

\begin{tabular}{|c|c|c|c|c|c|c|c|c|c|c|}
\hline \multirow[t]{2}{*}{$\begin{array}{c}R \\
(\mathrm{~Pa} / \mathrm{m})\end{array}$} & \multicolumn{2}{|c|}{$\begin{array}{l}\text { Dış çap=14 mm } \\
\text { Et kalınlığı=2 mm } \\
\text { İç çap=10 mm }\end{array}$} & \multicolumn{2}{|c|}{$\begin{array}{c}\text { Dış çap=16 mm } \\
\text { Et kalınlığı=2 mm } \\
\text { İç çap=12 mm }\end{array}$} & \multicolumn{2}{|c|}{$\begin{array}{l}\text { Dış çap=17 mm } \\
\text { Et kalınlığı=2 mm } \\
\text { İç çap=13 mm }\end{array}$} & \multicolumn{2}{|c|}{$\begin{array}{c}\text { Dış çap=18 mm } \\
\text { Et kalınlığı=2 mm } \\
\text { İç çap=14 mm }\end{array}$} & \multicolumn{2}{|c|}{$\begin{array}{c}\text { Dış çap=20 mm } \\
\text { Et kalınlığı=2,3 mm } \\
\text { İç çap=15,4 mm }\end{array}$} \\
\hline & $\mathrm{Q}(\mathrm{W})$ & $\mathrm{u}(\mathrm{m} / \mathrm{s})$ & $\mathrm{Q}(\mathrm{W})$ & $\mathrm{u}(\mathrm{m} / \mathrm{s})$ & $Q(W)$ & $\mathrm{u}(\mathrm{m} / \mathrm{s})$ & $\mathrm{Q}(\mathrm{W})$ & $\mathrm{u}(\mathrm{m} / \mathrm{s})$ & $\mathrm{Q}(\mathrm{W})$ & $\mathrm{u}(\mathrm{m} / \mathrm{s})$ \\
\hline 10 & 201,9 & 0,06 & 335,7 & 0,07 & 419,2 & 0,08 & 514,8 & 0,08 & 670 & 0,09 \\
\hline 20 & 304,7 & 0,09 & 504,9 & 0,11 & 629,7 & 0,12 & 772,4 & 0,12 & 1004 & 0,13 \\
\hline 30 & 386,9 & 0,12 & 639,9 & 0,14 & 797,5 & 0,15 & 977,5 & 0,15 & 1269 & 0,17 \\
\hline 40 & 457,9 & 0,14 & 756,3 & 0,16 & 942,2 & 0,17 & 1154 & 0,18 & 1498 & 0,20 \\
\hline 50 & 521,5 & 0,16 & 860,7 & 0,18 & 1072 & 0,20 & 1313 & 0,21 & 1703 & 0,22 \\
\hline 60 & 579,8 & 0,18 & 956,3 & 0,21 & 1190 & 0,22 & 1458 & 0,23 & 1890 & 0,25 \\
\hline 70 & 634,1 & 0,20 & 1045 & 0,22 & 1301 & 0,24 & 1592 & 0,25 & 2065 & 0,27 \\
\hline 80 & 685 & 0,21 & 1129 & 0,24 & 1404 & 0,26 & 1719 & 0,27 & 2228 & 0,29 \\
\hline 90 & 733,3 & 0,23 & 1208 & 0,26 & 1502 & 0,27 & 1838 & 0,29 & 2383 & 0,31 \\
\hline 100 & 779,3 & 0,24 & 1283 & 0,28 & 1596 & 0,29 & 1952 & 0,31 & 2530 & 0,33 \\
\hline 110 & 823,3 & 0,25 & 1355 & 0,29 & 1685 & 0,31 & 2061 & 0,32 & 2671 & 0,35 \\
\hline 120 & 865,5 & 0,27 & 1424 & 0,31 & 1771 & 0,32 & 2166 & 0,34 & 2806 & 0,37 \\
\hline 130 & 906,3 & 0,28 & 1491 & 0,32 & 1853 & 0,34 & 2267 & 0,36 & 2936 & 0,38 \\
\hline 140 & 945,7 & 0,29 & 1555 & 0,33 & 1933 & 0,35 & 2364 & 0,37 & 3062 & 0,40 \\
\hline 150 & 983,9 & 0,30 & 1617 & 0,35 & 2011 & 0,37 & 2459 & 0,39 & 3184 & 0,41 \\
\hline 160 & 1021 & 0,32 & 1678 & 0,36 & 2086 & 0,38 & 2550 & 0,40 & 3302 & 0,43 \\
\hline 170 & 1057 & 0,33 & 1737 & 0,37 & 2159 & 0,39 & 2640 & 0,42 & 3417 & 0,45 \\
\hline 180 & 1092 & 0,34 & 1794 & 0,38 & 2230 & 0,41 & 2726 & 0,43 & 3529 & 0,46 \\
\hline 190 & 1126 & 0,35 & 1850 & 0,40 & 2299 & 0,42 & 2811 & 0,44 & 3639 & 0,47 \\
\hline 200 & 1160 & 0,36 & 1905 & 0,41 & 2367 & 0,43 & 2894 & 0,46 & 3745 & 0,49 \\
\hline 210 & 1193 & 0,37 & 1958 & 0,42 & 2433 & 0,44 & 2975 & 0,47 & 3850 & 0,50 \\
\hline 220 & 1225 & 0,38 & 2011 & 0,43 & 2498 & 0,46 & 3054 & 0,48 & 3952 & 0,51 \\
\hline 230 & 1256 & 0,39 & 2062 & 0,44 & 2562 & 0,47 & 3131 & 0,49 & 4052 & 0,53 \\
\hline 240 & 1287 & 0,40 & 2112 & 0,45 & 2624 & 0,48 & 3207 & 0,51 & 4150 & 0,54 \\
\hline 250 & 1317 & 0,41 & 2162 & 0,46 & 2686 & 0,49 & 3282 & 0,52 & 4246 & 0,55 \\
\hline 260 & 1347 & 0,42 & 2210 & 0,47 & 2746 & 0,50 & 3355 & 0,53 & 4341 & 0,57 \\
\hline 270 & 1376 & 0,43 & 2258 & 0,48 & 2805 & 0,51 & 3427 & 0,54 & 4434 & 0,58 \\
\hline 280 & 1405 & 0,43 & 2305 & 0,49 & 2863 & 0,52 & 3498 & 0,55 & 4526 & 0,59 \\
\hline 290 & 1433 & 0,44 & 2351 & 0,50 & 2920 & 0,53 & 3568 & 0,56 & 4616 & 0,60 \\
\hline 300 & 1461 & 0,45 & 2397 & 0,51 & 2976 & 0,54 & 3637 & 0,57 & 4704 & 0,61 \\
\hline 310 & 1489 & 0,46 & 2441 & 0,52 & 3032 & 0,55 & 3704 & 0,58 & 4791 & 0,62 \\
\hline 320 & 1516 & 0,47 & 2485 & 0,53 & 3087 & 0,56 & 3771 & 0,59 & 4877 & 0,64 \\
\hline 330 & 1542 & 0,48 & 2529 & 0,54 & 3141 & 0,57 & 3837 & 0,60 & 4962 & 0,65 \\
\hline 340 & 1569 & 0,48 & 2572 & 0,55 & 3194 & 0,58 & 3902 & 0,61 & 5046 & 0,66 \\
\hline 350 & 1595 & 0,49 & 2614 & 0,56 & 3246 & 0,59 & 3966 & 0,63 & 5128 & 0,67 \\
\hline 360 & 1620 & 0,50 & 2656 & 0,57 & 3298 & 0,60 & 4029 & 0,64 & 5210 & 0,68 \\
\hline 370 & 1646 & 0,51 & 2697 & 0,58 & 3349 & 0,61 & 4091 & 0,64 & 5290 & 0,69 \\
\hline 380 & 1671 & 0,52 & 2738 & 0,59 & 3400 & 0,62 & 4153 & 0,65 & 5370 & 0,70 \\
\hline 390 & 1696 & 0,52 & 2779 & 0,60 & 3450 & 0,63 & 4214 & 0,66 & 5448 & 0,71 \\
\hline 400 & 1720 & 0,53 & 2818 & 0,60 & 3499 & 0,64 & 4274 & 0,67 & 5526 & 0,72 \\
\hline
\end{tabular}


Çizelge 1. Devam

\begin{tabular}{|c|c|c|c|c|c|c|c|c|c|c|}
\hline \multirow[t]{2}{*}{$\begin{array}{c}\mathrm{R} \\
(\mathrm{Pa} / \mathrm{m})\end{array}$} & \multicolumn{2}{|c|}{$\begin{array}{c}\text { Dış çap =25 mm } \\
\text { Et kalınlığı=2,8 mm } \\
\text { İç çap=19,4 mm }\end{array}$} & \multicolumn{2}{|c|}{$\begin{array}{c}\text { Dıs çap }=32 \mathrm{~mm} \\
\text { Et kalın lığı=3,6 mm } \\
\text { İç çap=24,8 mm }\end{array}$} & \multicolumn{2}{|c|}{$\begin{array}{c}\text { Dış çap }=40 \mathrm{~mm} \\
\text { Et kalın } ı \text { ı̆ı=6,7 mm } \\
\text { İç çap }=26,6 \mathrm{~mm}\end{array}$} & \multicolumn{2}{|c|}{$\begin{array}{c}\text { Dış çap=50 mm } \\
\text { Et kalın lığı=8,4 mm } \\
\text { İç çap }=33,2 \mathrm{~mm}\end{array}$} & \multicolumn{2}{|c|}{$\begin{array}{c}\text { Dış çap= } 63 \mathrm{~mm} \\
\text { Et kalınlığı }=10,5 \mathrm{~mm} \\
\text { İç çap }=42 \mathrm{~mm}\end{array}$} \\
\hline & $Q(W)$ & $\mathrm{u}(\mathrm{m} / \mathrm{s})$ & $\mathrm{Q}(\mathrm{W})$ & $\mathrm{u}(\mathrm{m} / \mathrm{s})$ & $Q(W)$ & $\mathrm{u}(\mathrm{m} / \mathrm{s})$ & $Q(W)$ & $\mathrm{u}(\mathrm{m} / \mathrm{s})$ & $\mathrm{Q}(\mathrm{W})$ & $\mathrm{u}(\mathrm{m} / \mathrm{s})$ \\
\hline 10 & 1266 & 0,10 & 2480 & 0,12 & 3003 & 0,13 & 5491 & 0,15 & 10390 & 0,18 \\
\hline 20 & 1890 & 0,16 & 3691 & 0,19 & 4465 & 0,19 & 8126 & 0,23 & 15370 & 0,27 \\
\hline 30 & 2385 & 0,20 & 4650 & 0,23 & 5623 & 0,25 & 10200 & 0,29 & 19300 & 0,34 \\
\hline 40 & 2811 & 0,23 & 5475 & 0,28 & 6619 & 0,29 & 11970 & 0,34 & 22680 & 0,40 \\
\hline 50 & 3193 & 0,26 & 6213 & 0,31 & 7508 & 0,33 & 13540 & 0,38 & 25690 & 0,45 \\
\hline 60 & 3542 & 0,29 & 6887 & 0,35 & 8321 & 0,36 & 14960 & 0,42 & 28430 & 0,50 \\
\hline 70 & 3866 & 0,32 & 7512 & 0,38 & 9075 & 0,40 & 16280 & 0,46 & 30980 & 0,54 \\
\hline 80 & 4170 & 0,34 & 8098 & 0,41 & 9782 & 0,43 & 17500 & 0,50 & 33370 & 0,58 \\
\hline 90 & 4457 & 0,37 & 8652 & 0,43 & 10450 & 0,46 & 18650 & 0,53 & 35620 & 0,62 \\
\hline 100 & 4730 & 0,39 & 9179 & 0,46 & 11090 & 0,48 & 19740 & 0,56 & 37760 & 0,66 \\
\hline 110 & 4992 & 0,41 & 9683 & 0,49 & 11690 & 0,51 & 20770 & 0,59 & 39810 & 0,70 \\
\hline 120 & 5243 & 0,43 & 10170 & 0,51 & 12280 & 0,54 & 21760 & 0,62 & 41770 & 0,73 \\
\hline 130 & 5484 & 0,45 & 10630 & 0,53 & 12840 & 0,56 & 22700 & 0,65 & 43660 & 0,76 \\
\hline 140 & 5718 & 0,47 & 11080 & 0,56 & 13380 & 0,58 & 23600 & 0,67 & 45480 & 0,80 \\
\hline 150 & 5944 & 0,49 & 11520 & 0,58 & 13900 & 0,61 & 24470 & 0,70 & 47250 & 0,83 \\
\hline 160 & 6164 & 0,51 & 11940 & 0,60 & 14410 & 0,63 & 25310 & 0,73 & 48960 & 0,86 \\
\hline 170 & 6377 & 0,52 & 12350 & 0,62 & 14910 & 0,65 & 26120 & 0,75 & 50620 & 0,89 \\
\hline 180 & 6585 & 0,54 & 12750 & 0,64 & 15390 & 0,67 & 26900 & 0,77 & 52240 & 0,91 \\
\hline 190 & 6787 & 0,56 & 13140 & 0,66 & 15860 & 0,69 & 27660 & 0,80 & 53820 & 0,94 \\
\hline 200 & 6985 & 0,57 & 13520 & 0,68 & 16320 & 0,71 & 28400 & 0,82 & 55360 & 0,97 \\
\hline 210 & 7179 & 0,59 & 13890 & 0,70 & 16770 & 0,73 & 29110 & 0,84 & 56860 & 1,00 \\
\hline 220 & 7368 & 0,60 & 14260 & 0,72 & 17210 & 0,75 & 29810 & 0,86 & 58330 & 1,02 \\
\hline 230 & 7553 & 0,62 & 14610 & 0,73 & 17640 & 0,77 & 30490 & 0,88 & 59780 & 1,05 \\
\hline 240 & 7735 & 0,63 & 14960 & 0,75 & 18060 & 0,79 & 31150 & 0,90 & 61190 & 1,07 \\
\hline 250 & 7914 & 0,65 & 15310 & 0,77 & 18470 & 0,81 & 31790 & 0,92 & 62570 & 1,10 \\
\hline 260 & 8089 & 0,66 & 15640 & 0,79 & 18880 & 0,82 & 32410 & 0,94 & 63930 & 1,12 \\
\hline 270 & 8261 & 0,68 & 15970 & 0,80 & 19270 & 0,84 & 33030 & 0,96 & 65270 & 1,14 \\
\hline 280 & 8430 & 0,69 & 16300 & 0,82 & 19670 & 0,86 & 33620 & 0,98 & 66580 & 1,17 \\
\hline 290 & 8597 & 0,71 & 16620 & 0,83 & 20050 & 0,88 & 34210 & 1,00 & 67870 & 1,19 \\
\hline 300 & 8761 & 0,72 & 16940 & 0,85 & 20430 & 0,89 & 34780 & 1,02 & 69140 & 1,21 \\
\hline 310 & 8923 & 0,73 & 17250 & 0,87 & 20800 & 0,91 & 35340 & 1,04 & 70400 & 1,23 \\
\hline 320 & 9082 & 0,75 & 17550 & 0,88 & 21170 & 0,92 & 35880 & 1,06 & 71630 & 1,25 \\
\hline 330 & 9239 & 0,76 & 17850 & 0,90 & 21540 & 0,94 & 36420 & 1,07 & 72840 & 1,28 \\
\hline 340 & 9393 & 0,77 & 18150 & 0,91 & 21890 & 0,96 & 36940 & 1,09 & 74040 & 1,30 \\
\hline 350 & 9546 & 0,78 & 18440 & 0,93 & 22250 & 0,97 & 37460 & 1,11 & 75220 & 1,32 \\
\hline 360 & 9697 & 0,80 & 18730 & 0,94 & 22600 & 0,99 & 37960 & 1,12 & 76390 & 1,34 \\
\hline 370 & 9846 & 0,81 & 19020 & 0,96 & 22940 & 1,00 & 38450 & 1,14 & 77540 & 1,36 \\
\hline 380 & 9993 & 0,82 & 19300 & 0,97 & 23280 & 1,02 & 38940 & 1,16 & 78680 & 1,38 \\
\hline 390 & 10140 & 0,83 & 19580 & 0,98 & 23610 & 1,03 & 39410 & 1,17 & 79800 & 1,40 \\
\hline 400 & 10280 & 0,84 & 19850 & 1,00 & 23950 & 1,05 & 39880 & 1,19 & 80910 & 1,42 \\
\hline
\end{tabular}


Isıtma Tesisatında Kullanılan Plastik Borular için Sürtünme Basınç Kaybı Gradyanı Çizelgesinin Hazırlanması ve Örnek Projeye Uygulanmast

Çizelge 1. Devam

\begin{tabular}{|c|c|c|c|c|c|c|c|c|c|c|}
\hline \multirow[t]{2}{*}{$\begin{array}{c}\text { R } \\
(\mathrm{Pa} / \mathrm{m})\end{array}$} & \multicolumn{2}{|c|}{$\begin{array}{c}\text { Dış çap=75 mm } \\
\text { Et kalınlığı=12,5 mm } \\
\text { İç çap= }=50 \mathrm{~mm}\end{array}$} & \multicolumn{2}{|c|}{$\begin{array}{c}\text { Dış çap=90 mm } \\
\text { Et kalınlığı=15 mm } \\
\text { İç çap=60 mm }\end{array}$} & \multicolumn{2}{|c|}{$\begin{array}{c}\text { Dış çap=110 mm } \\
\text { Et kalınlığı=18,3 mm } \\
\text { İç çap=73,4 mm }\end{array}$} & \multicolumn{2}{|c|}{$\begin{array}{c}\text { Dış çap=125 mm } \\
\text { Et kalınlığı=20,8 mm } \\
\text { İç çap=83,4 mm }\end{array}$} & \multicolumn{2}{|c|}{$\begin{array}{l}\text { Dış çap=160 mm } \\
\text { Et kalınlığı=26,6 mm } \\
\text { İç çap=106,8 mm }\end{array}$} \\
\hline & $\mathrm{Q}(\mathrm{W})$ & $\mathrm{u}(\mathrm{m} / \mathrm{s})$ & $\mathrm{Q}(\mathrm{W})$ & $\mathrm{u}(\mathrm{m} / \mathrm{s})$ & $\mathrm{Q}(\mathrm{W})$ & $\mathrm{u}(\mathrm{m} / \mathrm{s})$ & $\mathrm{Q}(\mathrm{W})$ & $\mathrm{u}(\mathrm{m} / \mathrm{s})$ & $\mathrm{Q}(\mathrm{W})$ & $\mathrm{u}(\mathrm{m} / \mathrm{s})$ \\
\hline 10 & 16640 & 0,21 & 27200 & 0,23 & 46770 & 0,27 & 65870 & 0,29 & 127700 & 0,35 \\
\hline 20 & 24580 & 0,30 & 40110 & 0,34 & 68840 & 0,39 & 96860 & 0,43 & 187400 & 0,51 \\
\hline 30 & 30840 & 0,38 & 50280 & 0,43 & 86210 & 0,49 & 121200 & 0,54 & 234300 & 0,63 \\
\hline 40 & 36210 & 0,45 & 58990 & 0,51 & 101100 & 0,58 & 142100 & 0,63 & 274400 & 0,74 \\
\hline 50 & 40990 & 0,51 & 66760 & 0,57 & 114300 & 0,66 & 160600 & 0,71 & 310000 & 0,84 \\
\hline 60 & 45360 & 0,56 & 73840 & 0,63 & 126400 & 0,72 & 177600 & 0,79 & 342500 & 0,93 \\
\hline 70 & 49400 & 0,61 & 80400 & 0,69 & 137600 & 0,79 & 193200 & 0,86 & 372600 & 1,01 \\
\hline 80 & 53190 & 0,66 & 86540 & 0,74 & 148000 & 0,85 & 207900 & 0,92 & 400700 & 1,09 \\
\hline 90 & 56770 & 0,70 & 92340 & 0,79 & 157900 & 0,91 & 221700 & 0,98 & 427300 & 1,16 \\
\hline 100 & 60170 & 0,74 & 97850 & 0,84 & 167300 & 0,96 & 234900 & 1,04 & 452500 & 1,23 \\
\hline 110 & 63420 & 0,78 & 103100 & 0,88 & 176300 & 1,01 & 247400 & 1,10 & 476500 & 1,29 \\
\hline 120 & 66540 & 0,82 & 108200 & 0,93 & 184800 & 1,06 & 259400 & 1,15 & 499500 & 1,35 \\
\hline 130 & 69530 & 0,86 & 113000 & 0,97 & 193100 & 1,11 & 271000 & 1,20 & 521700 & 1,41 \\
\hline 140 & 72430 & 0,89 & 117700 & 1,01 & 201100 & 1,15 & 282200 & 1,25 & 543100 & 1,47 \\
\hline 150 & 75220 & 0,93 & 122200 & 1,05 & 208800 & 1,20 & 293000 & 1,30 & 563800 & 1,53 \\
\hline 160 & 77940 & 0,96 & 126600 & 1,09 & 216300 & 1,24 & 303400 & 1,35 & 583800 & 1,58 \\
\hline 170 & 80580 & 1,00 & 130900 & 1,12 & 223500 & 1,28 & 313600 & 1,39 & 603200 & 1,63 \\
\hline 180 & 83140 & 1,03 & 135000 & 1,16 & 230600 & 1,32 & 323500 & 1,44 & 622200 & 1,69 \\
\hline 190 & 85640 & 1,06 & 139100 & 1,19 & 237500 & 1,36 & 333100 & 1,48 & 640600 & 1,74 \\
\hline 200 & 88080 & 1,09 & 143000 & 1,23 & 244200 & 1,40 & 342500 & 1,52 & 658600 & 1,78 \\
\hline 210 & 90470 & 1,12 & 146900 & 1,26 & 250700 & 1,44 & 351700 & 1,56 & 676200 & 1,83 \\
\hline 220 & 92800 & 1,15 & 150700 & 1,29 & 257100 & 1,47 & 360600 & 1,60 & 693300 & 1,88 \\
\hline 230 & 95090 & 1,18 & 154400 & 1,32 & 263400 & 1,51 & 369400 & 1,64 & 710100 & 1,92 \\
\hline 240 & 97320 & 1,20 & 158000 & 1,36 & 269600 & 1,55 & 378000 & 1,68 & 726600 & 1,97 \\
\hline 250 & 99520 & 1,23 & 161500 & 1,39 & 275600 & 1,58 & 386500 & 1,72 & 742800 & 2,01 \\
\hline 260 & 101700 & 1,26 & 165000 & 1,42 & 281500 & 1,61 & 394700 & 1,75 & 758600 & 2,05 \\
\hline 270 & 103800 & 1,28 & 168400 & 1,45 & 287400 & 1,65 & 402900 & 1,79 & 774200 & 2,10 \\
\hline 280 & 105900 & 1,31 & 171800 & 1,47 & 293100 & 1,68 & 410900 & 1,83 & 789400 & 2,14 \\
\hline 290 & 107900 & 1,33 & 175100 & 1,50 & 298700 & 1,71 & 418700 & 1,86 & 804500 & 2,18 \\
\hline 300 & 109900 & 1,36 & 178400 & 1,53 & 304200 & 1,74 & 426500 & 1,89 & 819300 & 2,22 \\
\hline 310 & 111900 & 1,38 & 181600 & 1,56 & 309700 & 1,78 & 434100 & 1,93 & 833800 & 2,26 \\
\hline 320 & 113900 & 1,41 & 184700 & 1,59 & 315000 & 1,81 & 441600 & 1,96 & 848100 & 2,30 \\
\hline 330 & 115800 & 1,43 & 187800 & 1,61 & 320300 & 1,84 & 449000 & 1,99 & 862300 & 2,34 \\
\hline 340 & 117700 & 1,45 & 190900 & 1,64 & 325500 & 1,87 & 456200 & 2,03 & 876200 & 2,37 \\
\hline 350 & 119600 & 1,48 & 193900 & 1,66 & 330600 & 1,90 & 463400 & 2,06 & 889900 & 2,41 \\
\hline 360 & 121400 & 1,50 & 196900 & 1,69 & 335700 & 1,93 & 470500 & 2,09 & 903500 & 2,45 \\
\hline 370 & 123200 & 1,52 & 199800 & 1,72 & 340700 & 1,95 & 477500 & 2,12 & 916800 & 2,48 \\
\hline 380 & 125000 & 1,55 & 202800 & 1,74 & 345700 & 1,98 & 484400 & 2,15 & 930000 & 2,52 \\
\hline 390 & 126800 & 1,57 & 205600 & 1,76 & 350500 & 2,01 & 491200 & 2,18 & 943000 & 2,55 \\
\hline 400 & 128600 & 1,59 & 208500 & 1,79 & 355400 & 2,04 & 498000 & 2,21 & 955900 & 2,59 \\
\hline
\end{tabular}


Çizelge 2. Çelik borularda $\Delta \mathrm{T}=10^{\circ} \mathrm{C}$ için pompalı tesisatta SBKG R çizelgesi

\begin{tabular}{|c|c|c|c|c|c|c|c|c|c|c|}
\hline \multirow{3}{*}{$\begin{array}{c}R \\
(\mathrm{~Pa} / \mathrm{m})\end{array}$} & \multicolumn{10}{|c|}{ Vidalı Yarı Ağır Borular DIN 2440} \\
\hline & \multicolumn{2}{|c|}{$d_{i c ̧}=15,75 \mathrm{~mm}$} & \multicolumn{2}{|c|}{$d_{i c ̧}=21,25 \mathrm{~mm}$} & \multicolumn{2}{|c|}{$\mathbf{d}_{\mathrm{iç}}=27 \mathrm{~mm}$} & \multicolumn{2}{|c|}{$\mathbf{d}_{\mathrm{iç}}=35,75 \mathrm{~mm}$} & \multicolumn{2}{|c|}{$d_{i c ̧}=41,25 \mathrm{~mm}$} \\
\hline & $\mathrm{Q}(\mathrm{W})$ & $\mathrm{u}(\mathrm{m} / \mathrm{s})$ & $Q(W)$ & $\mathrm{u}(\mathrm{m} / \mathrm{s})$ & $\mathrm{Q}(\mathrm{W})$ & $\mathrm{u}(\mathrm{m} / \mathrm{s})$ & $\mathrm{Q}(\mathrm{W})$ & $\mathrm{u}(\mathrm{m} / \mathrm{s})$ & $\mathrm{Q}(\mathrm{W})$ & $\mathrm{u}(\mathrm{m} / \mathrm{s})$ \\
\hline 10 & 652,7 & 0,08 & 1492 & 0,10 & 2878 & 0,12 & 6188 & 0,15 & 9125 & 0,17 \\
\hline 20 & 973,8 & 0,12 & 2215 & 0,15 & 4256 & 0,18 & 9114 & 0,22 & 13417 & 0,24 \\
\hline 30 & 1227 & 0,15 & 2784 & 0,19 & 5338 & 0,23 & 11406 & 0,28 & 16772 & 0,30 \\
\hline 40 & 1444 & 0,18 & 3270 & 0,22 & 6261 & 0,27 & 13359 & 0,32 & 19630 & 0,36 \\
\hline 50 & 1638 & 0,20 & 3702 & 0,25 & 7082 & 0,30 & 15093 & 0,36 & 22166 & 0,40 \\
\hline 60 & 1814 & 0,23 & 4096 & 0,28 & 7828 & 0,33 & 16668 & 0,40 & 24470 & 0,44 \\
\hline 70 & 1977 & 0,25 & 4460 & 0,31 & 8518 & 0,36 & 18124 & 0,44 & 26597 & 0,48 \\
\hline 80 & 2130 & 0,27 & 4800 & 0,33 & 9163 & 0,39 & 19483 & 0,47 & 28583 & 0,52 \\
\hline 90 & 2274 & 0,28 & 5121 & 0,35 & 9770 & 0,41 & 20762 & 0,50 & 30453 & 0,55 \\
\hline 100 & 2410 & 0,30 & 5426 & 0,37 & 10346 & 0,44 & 21976 & 0,53 & 32225 & 0,59 \\
\hline 110 & 2541 & 0,32 & 5716 & 0,39 & 10895 & 0,46 & 23132 & 0,56 & 33914 & 0,62 \\
\hline 120 & 2666 & 0,33 & 5994 & 0,41 & 11421 & 0,48 & 24239 & 0,59 & 35530 & 0,65 \\
\hline 130 & 2786 & 0,35 & 6261 & 0,43 & 11926 & 0,51 & 25302 & 0,61 & 37082 & 0,67 \\
\hline 140 & 2902 & 0,36 & 6519 & 0,45 & 12413 & 0,53 & 26327 & 0,64 & 38577 & 0,70 \\
\hline 150 & 3014 & 0,38 & 6768 & 0,46 & 12883 & 0,55 & 27316 & 0,66 & 40022 & 0,73 \\
\hline 160 & 3122 & 0,39 & 7009 & 0,48 & 13339 & 0,57 & 28274 & 0,68 & 41420 & 0,75 \\
\hline 170 & 3227 & 0,40 & 7243 & 0,50 & 13781 & 0,58 & 29204 & 0,71 & 42777 & 0,78 \\
\hline 180 & 3330 & 0,41 & 7470 & 0,51 & 14211 & 0,60 & 30107 & 0,73 & 44095 & 0,80 \\
\hline 190 & 3430 & 0,43 & 7692 & 0,53 & 14629 & 0,62 & 30987 & 0,75 & 45379 & 0,82 \\
\hline 200 & 3527 & 0,44 & 7908 & 0,54 & 15037 & 0,64 & 31844 & 0,77 & 46629 & 0,85 \\
\hline 210 & 3622 & 0,45 & 8119 & 0,56 & 15435 & 0,65 & 32681 & 0,79 & 47850 & 0,87 \\
\hline 220 & 3715 & 0,46 & 8325 & 0,57 & 15824 & 0,67 & 33498 & 0,81 & 49042 & 0,89 \\
\hline 230 & 3806 & 0,47 & 8526 & 0,58 & 16205 & 0,69 & 34298 & 0,83 & 50209 & 0,91 \\
\hline 240 & 3895 & 0,49 & 8724 & 0,60 & 16577 & 0,70 & 35080 & 0,85 & 51351 & 0,93 \\
\hline 250 & 3982 & 0,50 & 8917 & 0,61 & 16942 & 0,72 & 35847 & 0,87 & 52470 & 0,95 \\
\hline 260 & 4067 & 0,51 & 9107 & 0,62 & 17301 & 0,73 & 36600 & 0,88 & 53567 & 0,97 \\
\hline 270 & 4151 & 0,52 & 9294 & 0,64 & 17652 & 0,75 & 37338 & 0,90 & 54643 & 0,99 \\
\hline 280 & 4234 & 0,53 & 9477 & 0,65 & 17997 & 0,76 & 38063 & 0,92 & 55701 & 1,01 \\
\hline 290 & 4315 & 0,54 & 9656 & 0,66 & 18337 & 0,78 & 38775 & 0,94 & 56740 & 1,03 \\
\hline 300 & 4395 & 0,55 & 9833 & 0,67 & 18670 & 0,79 & 39476 & 0,95 & 57761 & 1,05 \\
\hline 310 & 4473 & 0,56 & 10007 & 0,68 & 18999 & 0,81 & 40165 & 0,97 & 58767 & 1,07 \\
\hline 320 & 4551 & 0,57 & 10179 & 0,70 & 19322 & 0,82 & 40844 & 0,99 & 59756 & 1,09 \\
\hline 330 & 4627 & 0,58 & 10348 & 0,71 & 19640 & 0,83 & 41512 & 1,00 & 60730 & 1,10 \\
\hline 340 & 4702 & 0,59 & 10514 & 0,72 & 19954 & 0,85 & 42170 & 1,02 & 61690 & 1,12 \\
\hline 350 & 4776 & 0,59 & 10678 & 0,73 & 20263 & 0,86 & 42819 & 1,04 & 62636 & 1,14 \\
\hline 360 & 4849 & 0,60 & 10840 & 0,74 & 20568 & 0,87 & 43459 & 1,05 & 63569 & 1,15 \\
\hline 370 & 4921 & 0,61 & 10999 & 0,75 & 20869 & 0,88 & 44090 & 1,07 & 64489 & 1,17 \\
\hline 380 & 4992 & 0,62 & 11157 & 0,76 & 21166 & 0,90 & 44713 & 1,08 & 65397 & 1,19 \\
\hline 390 & 5062 & 0,63 & 11312 & 0,77 & 21459 & 0,91 & 45328 & 1,10 & 66294 & 1,20 \\
\hline 400 & 5132 & 0,64 & 11466 & 0,78 & 21748 & 0,92 & 45935 & 1,11 & 67179 & 1,22 \\
\hline
\end{tabular}


Isıtma Tesisatında Kullanılan Plastik Borular için Sürtünme Basınç Kaybı Gradyanı Çizelgesinin Hazırlanması ve Örnek Projeye Uygulanmast

Çizelge 2. devamı

\begin{tabular}{|c|c|c|c|c|c|c|c|c|c|c|c|c|}
\hline \multirow{3}{*}{$\begin{array}{c}R \\
(\mathrm{~Pa} / \mathrm{m})\end{array}$} & \multicolumn{12}{|c|}{ Dikişsiz Çelik Borular DIN 2449} \\
\hline & \multicolumn{2}{|c|}{$\mathrm{d}_{\mathrm{iç}}=39,5 \mathrm{~mm}$} & \multicolumn{2}{|c|}{$\mathrm{d}_{\mathrm{iç}}=51,5 \mathrm{~mm}$} & \multicolumn{2}{|c|}{$\mathrm{d}_{\mathrm{ic}}=64 \mathrm{~mm}$} & \multicolumn{2}{|c|}{$\mathbf{d}_{\mathrm{icc}}=\mathbf{7 0} \mathrm{mm}$} & \multicolumn{2}{|c|}{$\mathrm{d}_{\mathrm{ic}}=82,5 \mathrm{~mm}$} & \multicolumn{2}{|c|}{$d_{i c ̧}=100,5 \mathrm{~mm}$} \\
\hline & $Q(W)$ & $u(m / s)$ & $Q(W)$ & $u(m / s)$ & $Q(W)$ & $u(m / s)$ & $Q(W)$ & $\mathrm{u}(\mathrm{m} / \mathrm{s})$ & $Q(W)$ & $u(m / s)$ & $Q(W)$ & $\mathrm{u}(\mathrm{m} / \mathrm{s})$ \\
\hline 10 & 8113 & 0,16 & 16636 & 0,19 & 29883 & 0,23 & 38024 & 0,24 & 59094 & 0,27 & 100219 & 0,31 \\
\hline 20 & 11935 & 0,24 & 24392 & 0,28 & 43706 & 0,33 & 55560 & 0,35 & 86197 & 0,39 & 145896 & 0,45 \\
\hline 30 & 14924 & 0,30 & 30446 & 0,35 & 54479 & 0,41 & 69216 & 0,44 & 107281 & 0,49 & 181382 & 0,55 \\
\hline 40 & 17472 & 0,35 & 35598 & 0,41 & 63637 & 0,48 & 80821 & 0,51 & 125186 & 0,57 & 211496 & 0,65 \\
\hline 50 & 19732 & 0,39 & 40165 & 0,47 & 71749 & 0,54 & 91099 & 0,57 & 141036 & 0,64 & 238140 & 0,73 \\
\hline 60 & 21785 & 0,43 & 44312 & 0,52 & 79113 & 0,60 & 100426 & 0,63 & 155414 & 0,71 & 262300 & 0,80 \\
\hline 70 & 23681 & 0,47 & 48138 & 0,56 & 85904 & 0,65 & 109027 & 0,69 & 168670 & 0,77 & 284568 & 0,87 \\
\hline 80 & 25452 & 0,50 & 51710 & 0,60 & 92241 & 0,70 & 117051 & 0,74 & 181033 & 0,82 & 305332 & 0,93 \\
\hline 90 & 27119 & 0,54 & 55072 & 0,64 & 98204 & 0,74 & 124601 & 0,79 & 192665 & 0,87 & 324863 & 0,99 \\
\hline 100 & 28699 & 0,57 & 58257 & 0,68 & 103853 & 0,78 & 131753 & 0,83 & 203681 & 0,92 & 343357 & 1,05 \\
\hline 110 & 30205 & 0,60 & 61292 & 0,71 & 109234 & 0,82 & 138564 & 0,87 & 214171 & 0,97 & 360966 & 1,10 \\
\hline 120 & 31646 & 0,63 & 64196 & 0,75 & 114381 & 0,86 & 145080 & 0,91 & 224205 & 1,02 & 377806 & 1,16 \\
\hline 130 & 33030 & 0,65 & 66984 & 0,78 & 119323 & 0,90 & 151335 & 0,95 & 233836 & 1,06 & 393969 & 1,21 \\
\hline 140 & 34364 & 0,68 & 69670 & 0,81 & 124082 & 0,94 & 157359 & 0,99 & 243111 & 1,10 & 409533 & 1,25 \\
\hline 150 & 35652 & 0,71 & 72264 & 0,84 & 128679 & 0,97 & 163176 & 1,03 & 252067 & 1,14 & 424559 & 1,30 \\
\hline 160 & 36899 & 0,73 & 74775 & 0,87 & 133127 & 1,00 & 168806 & 1,06 & 260734 & 1,18 & 439099 & 1,34 \\
\hline 170 & 38109 & 0,75 & 77211 & 0,90 & 137442 & 1,04 & 174267 & 1,10 & 269138 & 1,22 & 453199 & 1,39 \\
\hline 180 & 39285 & 0,78 & 79578 & 0,93 & 141634 & 1,07 & 179571 & 1,13 & 277303 & 1,26 & 466895 & 1,43 \\
\hline 190 & 40429 & 0,80 & 81881 & 0,95 & 145713 & 1,10 & 184733 & 1,17 & 285248 & 1,30 & 480221 & 1,47 \\
\hline 200 & 41545 & 0,82 & 84125 & 0,98 & 149688 & 1,13 & 189764 & 1,20 & 292990 & 1,33 & 493206 & 1,51 \\
\hline 210 & 42634 & 0,84 & 86316 & 1,01 & 153567 & 1,16 & 194672 & 1,23 & 300543 & 1,36 & 505874 & 1,55 \\
\hline 220 & 43697 & 0,87 & 88456 & 1,03 & 157356 & 1,19 & 199466 & 1,26 & 307921 & 1,40 & 518247 & 1,59 \\
\hline 230 & 44738 & 0,89 & 90549 & 1,06 & 161062 & 1,22 & 204155 & 1,29 & 315135 & 1,43 & 530346 & 1,62 \\
\hline 240 & 45756 & 0,91 & 92597 & 1,08 & 164689 & 1,24 & 208744 & 1,32 & 322197 & 1,46 & 542188 & 1,66 \\
\hline 250 & 46754 & 0,93 & 94605 & 1,10 & 168242 & 1,27 & 213240 & 1,34 & 329114 & 1,49 & 553788 & 1,69 \\
\hline 260 & 47733 & 0,95 & 96573 & 1,13 & 171726 & 1,30 & 217648 & 1,37 & 335897 & 1,52 & 565161 & 1,73 \\
\hline 270 & 48693 & 0,96 & 98504 & 1,15 & 175145 & 1,32 & 221973 & 1,40 & 342552 & 1,56 & 576320 & 1,76 \\
\hline 280 & 49636 & 0,98 & 100401 & 1,17 & 178502 & 1,35 & 226221 & 1,43 & 349086 & 1,58 & 587276 & 1,80 \\
\hline 290 & 50563 & 1,00 & 102264 & 1,19 & 181801 & 1,37 & 230394 & 1,45 & 355506 & 1,61 & 598040 & 1,83 \\
\hline 300 & 51475 & 1,02 & 104097 & 1,21 & 185044 & 1,40 & 234496 & 1,48 & 361818 & 1,64 & 608622 & 1,86 \\
\hline 310 & 52371 & 1,04 & 105899 & 1,23 & 188234 & 1,42 & 238532 & 1,50 & 368026 & 1,67 & 619031 & 1,89 \\
\hline 320 & 53254 & 1,05 & 107673 & 1,25 & 191374 & 1,44 & 242504 & 1,53 & 374137 & 1,70 & 629274 & 1,93 \\
\hline 330 & 54123 & 1,07 & 109420 & 1,27 & 194466 & 1,47 & 246415 & 1,55 & 380153 & 1,73 & 639361 & 1,96 \\
\hline 340 & 54979 & 1,09 & 111141 & 1,29 & 197511 & 1,49 & 250268 & 1,58 & 386080 & 1,75 & 649297 & 1,99 \\
\hline 350 & 55823 & 1,11 & 112838 & 1,31 & 200513 & 1,51 & 254066 & 1,60 & 391922 & 1,78 & 659089 & 2,02 \\
\hline 360 & 56655 & 1,12 & 114511 & 1,33 & 203473 & 1,53 & 257810 & 1,63 & 397681 & 1,81 & 668744 & 2,05 \\
\hline 370 & 57476 & 1,14 & 116161 & 1,35 & 206393 & 1,56 & 261504 & 1,65 & 403362 & 1,83 & 678267 & 2,07 \\
\hline 380 & 58286 & 1,15 & 117789 & 1,37 & 209274 & 1,58 & 265148 & 1,67 & 408967 & 1,86 & 687662 & 2,10 \\
\hline 390 & 59086 & 1,17 & 119396 & 1,39 & 212117 & 1,60 & 268745 & 1,69 & 414500 & 1,88 & 696937 & 2,13 \\
\hline 400 & 59876 & 1,19 & 120983 & 1,41 & 214925 & 1,62 & 272297 & 1,72 & 419963 & 1,91 & 706094 & 2,16 \\
\hline
\end{tabular}


Çizelge 2. devamı

\begin{tabular}{|c|c|c|c|c|c|c|c|c|c|c|c|c|c|c|}
\hline \multirow{3}{*}{$\begin{array}{c}R \\
(\mathrm{~Pa} / \mathrm{m})\end{array}$} & \multicolumn{14}{|c|}{ Dikişsiz Çelik Borular DIN 2449} \\
\hline & \multicolumn{2}{|c|}{$\mathrm{d}_{\mathrm{ic}}=113 \mathrm{~mm}$} & \multicolumn{2}{|c|}{$\mathrm{d}_{\mathrm{ic}}=125 \mathrm{~mm}$} & \multicolumn{2}{|c|}{$d_{i c ̧}=150 \mathrm{~mm}$} & \multicolumn{2}{|c|}{$\mathrm{d}_{\mathrm{iç}}=180 \mathrm{~mm}$} & \multicolumn{2}{|c|}{$\mathrm{d}_{\mathrm{iç}}=204 \mathrm{~mm}$} & \multicolumn{2}{|c|}{$\mathrm{d}_{\mathrm{ic}}=228 \mathrm{~mm}$} & \multicolumn{2}{|c|}{$\mathrm{d}_{\mathrm{ic}}=254 \mathrm{~mm}$} \\
\hline & $Q(W)$ & $\mathrm{u}(\mathrm{m} / \mathrm{s})$ & $\mathrm{Q}(\mathrm{W})$ & $u(m / s)$ & $Q(W)$ & $\mathrm{u}(\mathrm{m} / \mathrm{s})$ & $\mathrm{Q}(\mathrm{W})$ & $\mathrm{u}(\mathrm{m} / \mathrm{s})$ & $\mathrm{Q}(\mathrm{W})$ & $\mathrm{u}(\mathrm{m} / \mathrm{s})$ & $\mathrm{Q}(\mathrm{W})$ & $\mathrm{u}(\mathrm{m} / \mathrm{s})$ & $\mathrm{Q}(\mathrm{W})$ & $u(m / s)$ \\
\hline 10 & 137064 & 0,33 & 179396,2 & 0,35 & 291472,7 & 0,40 & 473063,8 & 0,45 & 659250,4 & 0,49 & 885044,2 & 0,53 & 1177639 & 0,56 \\
\hline 20 & 199308 & 0,48 & 260620,4 & 0,52 & 422750,3 & 0,58 & 685062,2 & 0,65 & 953707,8 & 0,71 & 1279223 & 0,76 & 1700715 & 0,81 \\
\hline 30 & 247632 & 0,60 & 323641,3 & 0,64 & 524502,6 & 0,72 & 849223 & 0,81 & 1181579 & 0,88 & 1584104 & 0,94 & 2105095 & 1,01 \\
\hline 40 & 288622 & 0,70 & 377080,4 & 0,75 & 610733,5 & 0,84 & 988266,8 & 0,94 & 1374518 & 1,02 & 1842172 & 1,10 & 2447291 & 1,17 \\
\hline 50 & 324879 & 0,79 & 424336,6 & 0,84 & 686957,2 & 0,94 & 1111130 & 1,06 & 1544964 & 1,15 & 2070110 & 1,23 & 2749482 & 1,32 \\
\hline 60 & 357749 & 0,87 & 467171,8 & 0,92 & 756029,9 & 1,04 & 1222436 & 1,17 & 1699352 & 1,26 & 2276545 & 1,35 & 3023128 & 1,45 \\
\hline 70 & 388040 & 0,94 & 506640,8 & 1,00 & 819659,9 & 1,13 & 1324951 & 1,26 & 1841527 & 1,37 & 2466629 & 1,47 & 3275076 & 1,57 \\
\hline 80 & 416281 & 1,01 & \begin{tabular}{|l|}
543434,6 \\
\end{tabular} & 1,07 & 878966,2 & 1,21 & 1420484 & 1,35 & 1974006 & 1,47 & 2643733 & 1,57 & 3509802 & 1,68 \\
\hline 90 & 442841 & 1,07 & 578035,3 & 1,14 & 934729,2 & 1,28 & 1510297 & 1,44 & 2098542 & 1,56 & 2810208 & 1,67 & 3730426 & 1,79 \\
\hline 100 & 467991 & 1,13 & 610795,8 & 1,21 & 987519,2 & 1,36 & 1595312 & 1,52 & 2216417 & 1,65 & 2967769 & 1,76 & 3939225 & 1,89 \\
\hline 110 & 491934 & 1,19 & 641982,1 & 1,27 & 1037768 & 1,43 & 1676228 & 1,60 & 2328600 & 1,73 & 3117715 & 1,85 & 4137924 & 1,98 \\
\hline 120 & 514829 & 1,25 & 671802,5 & 1,33 & 1085812 & 1,49 & 1753584 & 1,67 & 2435845 & 1,81 & 3261053 & 1,94 & 4327859 & 2,07 \\
\hline 130 & 536804 & 1,30 & 700422,9 & 1,39 & 1131918 & 1,55 & 1827816 & 1,74 & 2538752 & 1,88 & 3398589 & 2,02 & 4510099 & 2,16 \\
\hline 140 & 557962 & 1,35 & \begin{tabular}{|l|}
727977,8 \\
\end{tabular} & 1,44 & 1176304 & 1,62 & 1899275 & 1,81 & 2637810 & 1,96 & 3530977 & 2,10 & 4685513 & 2,24 \\
\hline 150 & 578388 & 1,40 & 754578,3 & 1,49 & 1219150 & 1,67 & 1968250 & 1,88 & 2733422 & 2,03 & 3658755 & 2,17 & 4854815 & 2,32 \\
\hline 160 & 598153 & 1,45 & 780317,6 & 1,54 & 1260606 & 1,73 & 2034984 & 1,94 & 2825926 & 2,10 & 3782375 & 2,25 & 5018604 & 2,40 \\
\hline 170 & 617318 & 1,49 & 805274,4 & 1,59 & 1300800 & 1,79 & 2099683 & 2,00 & 2915605 & 2,16 & 3902219 & 2,32 & 5177385 & 2,48 \\
\hline 180 & 635935 & 1,54 & 829516,2 & 1,64 & 1339841 & 1,84 & 2162523 & 2,06 & 3002705 & 2,23 & 4018613 & 2,39 & 5331593 & 2,55 \\
\hline 190 & 654047 & 1,58 & 853101,3 & 1,69 & 1377822 & 1,89 & 2223655 & 2,12 & 3087436 & 2,29 & 4131839 & 2,46 & 5481601 & 2,63 \\
\hline 200 & 671695 & 1,63 & 876080,4 & 1,73 & 1414826 & 1,94 & 2283212 & 2,18 & 3169982 & 2,35 & 4242143 & 2,52 & 5627736 & 2,70 \\
\hline 210 & 688912 & 1,67 & 898498,1 & 1,78 & 1450925 & 1,99 & 2341310 & 2,23 & 3250504 & 2,41 & 4349741 & 2,59 & 5770283 & 2,76 \\
\hline 220 & 705728 & 1,71 & 920393,7 & 1,82 & 1486181 & 2,04 & 2398051 & 2,29 & 3329144 & 2,47 & 4454822 & 2,65 & 5909494 & 2,83 \\
\hline 230 & 722171 & 1,75 & \begin{tabular}{|l|}
941802,2 \\
\end{tabular} & 1,86 & 1520652 & 2,09 & 2453526 & 2,34 & 3406028 & 2,53 & 4557556 & 2,71 & 6045594 & 2,90 \\
\hline 240 & 738264 & 1,79 & 962754,7 & 1,90 & 1554388 & 2,13 & 2507817 & 2,39 & 3481269 & 2,58 & 4658093 & 2,77 & 6178782 & 2,96 \\
\hline 250 & 754028 & 1,82 & 983279,2 & 1,94 & 1587434 & 2,18 & 2560995 & 2,44 & 3554969 & 2,64 & 4756568 & 2,83 & 6309237 & 3,02 \\
\hline 260 & 769483 & 1,86 & 1003401 & 1,98 & 1619831 & 2,22 & 2613128 & 2,49 & 3627217 & 2,69 & 4853104 & 2,88 & 6437122 & 3,08 \\
\hline 270 & 784647 & 1,90 & 1023143 & 2,02 & 1651615 & 2,27 & 2664274 & 2,54 & 3698098 & 2,75 & 4947811 & 2,94 & 6562582 & 3,14 \\
\hline 280 & 799535 & 1,93 & 1042526 & 2,06 & 1682820 & 2,31 & 2714488 & 2,59 & 3767685 & 2,80 & \begin{tabular}{|l|}
5040789 \\
\end{tabular} & 3,00 & 6685751 & 3,20 \\
\hline 290 & 814162 & 1,97 & 1061569 & 2,10 & 1713477 & 2,35 & 2763818 & 2,64 & 3836047 & 2,85 & 5132129 & 3,05 & 6806749 & 3,26 \\
\hline 300 & 828541 & 2,00 & 1080288 & 2,14 & 1743613 & 2,39 & 2812311 & 2,68 & 3903247 & 2,90 & 5221916 & 3,10 & 6925689 & 3,32 \\
\hline 310 & 842684 & 2,04 & 1098701 & 2,17 & 1773255 & 2,43 & 2860006 & 2,73 & 3969342 & 2,95 & 5310226 & 3,16 & 7042670 & 3,37 \\
\hline 320 & 856604 & 2,07 & 1116822 & 2,21 & 1802426 & 2,48 & 2906943 & 2,77 & 4034385 & 3,00 & 5397129 & 3,21 & 7157788 & 3,43 \\
\hline 330 & 870309 & 2,11 & 1134664 & 2,24 & 1831148 & 2,51 & 2953155 & 2,82 & 4098425 & 3,04 & 5482691 & 3,26 & 7271129 & 3,48 \\
\hline 340 & 883810 & 2,14 & 1152240 & 2,28 & 1859440 & 2,55 & 2998677 & 2,86 & 4161506 & 3,09 & 5566972 & 3,31 & 7382772 & 3,54 \\
\hline 350 & 897115 & 2,17 & 1169560 & 2,31 & 1887322 & 2,59 & 3043538 & 2,90 & 4223671 & 3,14 & 5650027 & 3,36 & 7492791 & 3,59 \\
\hline 360 & 910233 & 2,20 & 1186637 & 2,35 & 1914811 & 2,63 & 3087766 & 2,94 & 4284958 & 3,18 & 5731910 & 3,41 & 7601256 & 3,64 \\
\hline 370 & 923172 & 2,23 & 1203481 & 2,38 & 1941923 & 2,67 & 3131387 & 2,99 & 4345404 & 3,23 & 5812668 & 3,45 & 7708230 & 3,69 \\
\hline 380 & 935938 & 2,26 & 1220099 & 2,41 & 1968673 & 2,70 & 3174425 & 3,03 & 4405041 & 3,27 & 5892346 & 3,50 & 7813774 & 3,74 \\
\hline 390 & 948539 & 2,30 & 1236502 & 2,44 & 1995076 & 2,74 & 3216904 & 3,07 & 4463903 & 3,31 & 5970987 & 3,55 & 7917943 & 3,79 \\
\hline 400 & 960980 & 2,33 & 1252697 & 2,48 & 2021144 & 2,78 & 3258844 & 3,11 & 4522018 & 3,36 & 6048630 & 3,59 & 8020789 & 3,84 \\
\hline
\end{tabular}

ve toplam su debisi de,

$\dot{V}=\frac{\dot{Q}}{\rho c_{p} * \Delta T}=\frac{238 \mathrm{~kW}}{985\left(\frac{\mathrm{kg}}{\mathrm{m}^{3}}\right) * 4,182\left(\frac{\mathrm{kJ}}{\mathrm{kg}^{\circ} \mathrm{C}}\right) * 10\left({ }^{\circ} \mathrm{C}\right)}$
$\dot{V}=5,77 * 10^{-3} \frac{\mathrm{m}^{3}}{\mathrm{~s}}=20,79 \frac{\mathrm{m}^{3}}{\mathrm{~h}}$

olarak elde edilir. Pompa seçilirken yine pompa karakteristik eğrisi ve pompa verim eğrisi dikkate alınmalıdır. 
Isıtma Tesisatında Kullanılan Plastik Borular için Sürtünme Basınç Kaybı Gradyanı Çizelgesinin Hazırlanması ve Örnek Projeye Uygulanması

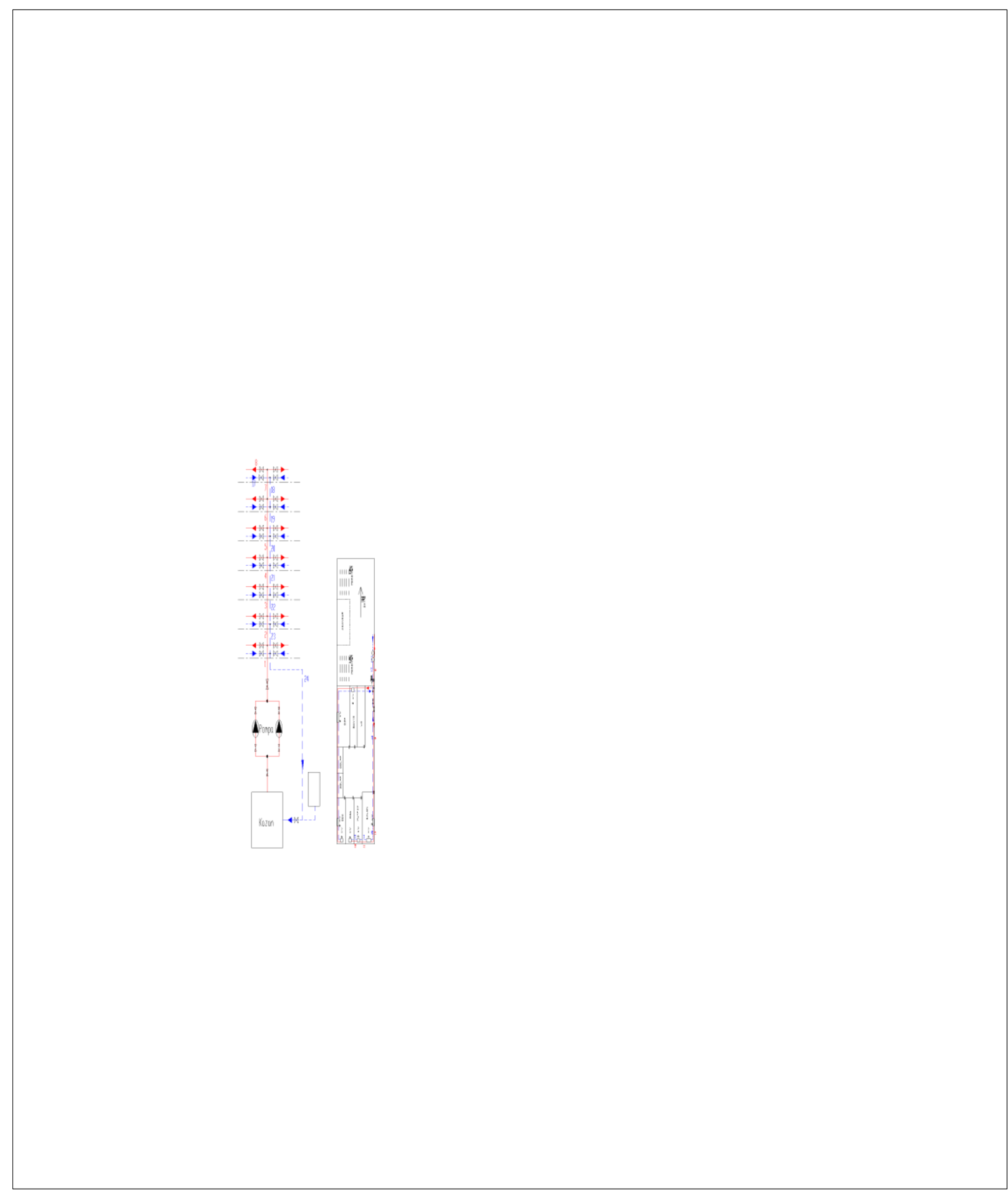

Şekil 3. Örnek tesisatın kolon şeması ve daire kat planı 
Çizelge 3. Plastik boru için $\zeta$ değerleri

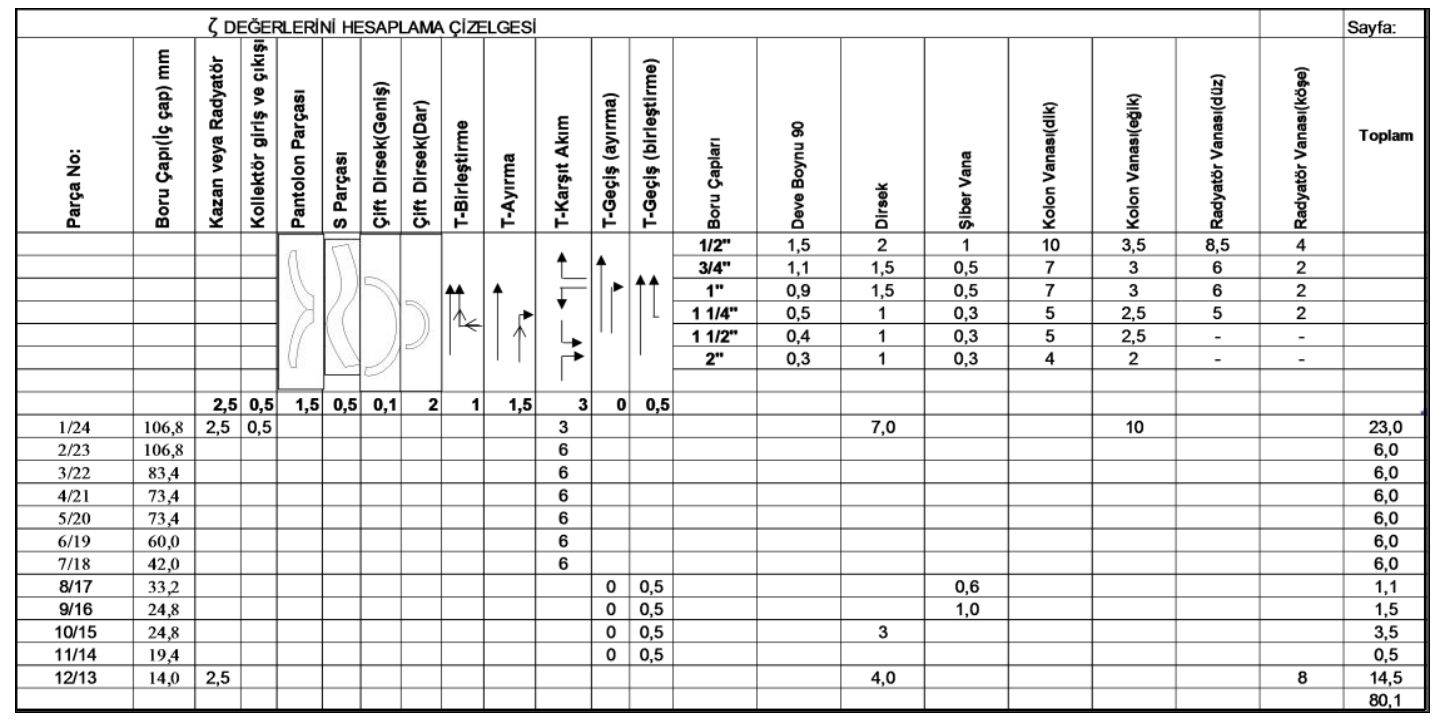

Çizelge 4. Plastik boru için boru hesap cetveli

\begin{tabular}{|c|c|c|c|c|c|c|c|c|c|c|c|c|c|c|c|c|c|}
\hline \multirow[b]{3}{*}{ a } & \multirow[b]{3}{*}{$b$} & \multicolumn{6}{|c|}{ Boru Hesabı Cetveli } & & & & & & & & \multirow{2}{*}{\multicolumn{3}{|c|}{$\begin{array}{l}\text { Sahife: } \\
\text { Kat: }\end{array}$}} \\
\hline & & \multirow[b]{2}{*}{ C } & \multirow[b]{2}{*}{$d$} & \multirow[b]{2}{*}{$\mathrm{e}$} & \multicolumn{3}{|r|}{ Binası } & \multirow[b]{2}{*}{1} & \multirow[b]{2}{*}{$\mathrm{k}$} & \multirow[b]{2}{*}{1} & \multirow[b]{2}{*}{$\mathrm{m}$} & \multirow[b]{2}{*}{$\mathrm{n}$} & \multirow[b]{2}{*}{0} & \multirow{2}{*}{\begin{tabular}{l|l} 
& \\
$p$
\end{tabular}} & & & \\
\hline & & & & & $f$ & $\mathrm{~g}$ & $\mathrm{~h}$ & & & & & & & & \multicolumn{3}{|c|}{\begin{tabular}{l|l|l}
$q$ & $r$ & $s$
\end{tabular}} \\
\hline \multirow{2}{*}{ 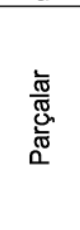 } & \multirow{2}{*}{ 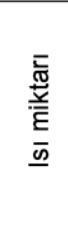 } & \multirow{2}{*}{ 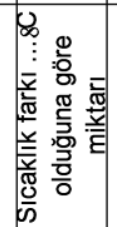 } & \multirow{2}{*}{ 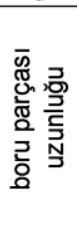 } & \multicolumn{6}{|c|}{ Takribi boru Çapına Göre } & \multicolumn{6}{|c|}{$\begin{array}{c}\text { Değiştirilmiş Boru Çapına } \\
\text { Göre }\end{array}$} & \multicolumn{2}{|c|}{ Fark } \\
\hline & & & & d & u & $\mathrm{R}$ & LR & $\Sigma \varphi$ & Z & d & u & $\mathrm{R}$ & LR & $\mathbf{v}$ & $\varphi$ & LR & Z \\
\hline No & kW & Watt & $\mathbf{m}$ & $\mathrm{mm}$ & $\mathrm{m} / \mathrm{s}$ & $\mathrm{Pa} / \mathrm{m}$ & $\mathrm{Pa}$ & & $\mathbf{P a}$ & & $\mathrm{m} / \mathrm{b}$ & $\mathrm{Pa} / \mathrm{m}$ & $\mathbf{P a}$ & & $\mathrm{Pa}$ & $\mathbf{P a}$ & $\mathbf{P a}$ \\
\hline $1 / 24$ & 238 & & 10 & 107 & 0,64 & 30,88 & 308,80 & 23,0 & 4710 & & & & & & & & \\
\hline $2 / 23$ & 204 & & 6 & 107 & 0,55 & 23,33 & 139,98 & 6,0 & 908 & & & & & & & & \\
\hline $3 / 22$ & 170 & & 6 & 83,4 & 0,75 & 55,42 & 332,52 & 6,0 & 1688 & & & & & & & & \\
\hline $4 / 21$ & 136 & & 6 & 73,4 & 0,77 & 68,50 & 411,00 & 6,0 & 1779 & & & & & & & & \\
\hline $5 / 20$ & 102 & & 6 & 73,4 & 0,58 & 40,67 & 244,02 & 6,0 & 1009 & & & & & & & & \\
\hline $6 / 19$ & 68 & & 6 & 60 & 0,58 & 51,70 & 310,20 & 6,0 & 1009 & & & & & & & & \\
\hline $7 / 18$ & 34 & & 6 & 42 & 0,59 & 82,70 & 496,20 & 6,0 & 1044 & & & & & & & & \\
\hline $8 / 17$ & 17 & & 4 & 33,2 & 0,47 & 73,90 & 295,60 & 1,1 & 121 & & & & & & & & \\
\hline $9 / 16$ & 9 & & 16 & 24,8 & 0,45 & 96,50 & $1.544,00$ & 1,5 & 152 & & & & & & & & \\
\hline $10 / 15$ & 7 & & 6 & 24,8 & 0,35 & 61,70 & 370,20 & 3,5 & 214 & & & & & & & & \\
\hline $11 / 14$ & 4 & & 8 & 19,4 & 0,32 & 74,30 & 594,40 & 0,5 & 25,6 & & & & & & & & \\
\hline \multirow[t]{5}{*}{$12 / 13$} & 2 & & 6 & 14 & 0,31 & 104,30 & 625,80 & 14,5 & 697 & & & & & & & & \\
\hline & & & & & & & & & & & & & & & & & \\
\hline & \multicolumn{6}{|c|}{ TOPLAM LR = } & $5.672,72$ & \multicolumn{3}{|c|}{ TOPLAM Z = } & \multicolumn{3}{|c|}{$13.356,87$} & & & & \\
\hline & & & & & & & & & & & & & & & & & \\
\hline & & & GE & NEL T & OPLA & $M=$ & & 9,59 & & $\mathbf{P}$ & & & & & & & \\
\hline
\end{tabular}


Isıtma Tesisatında Kullanılan Plastik Borular için Sürtünme Basınç Kaybı Gradyanı Çizelgesinin Hazırlanması ve Örnek Projeye Uygulanması

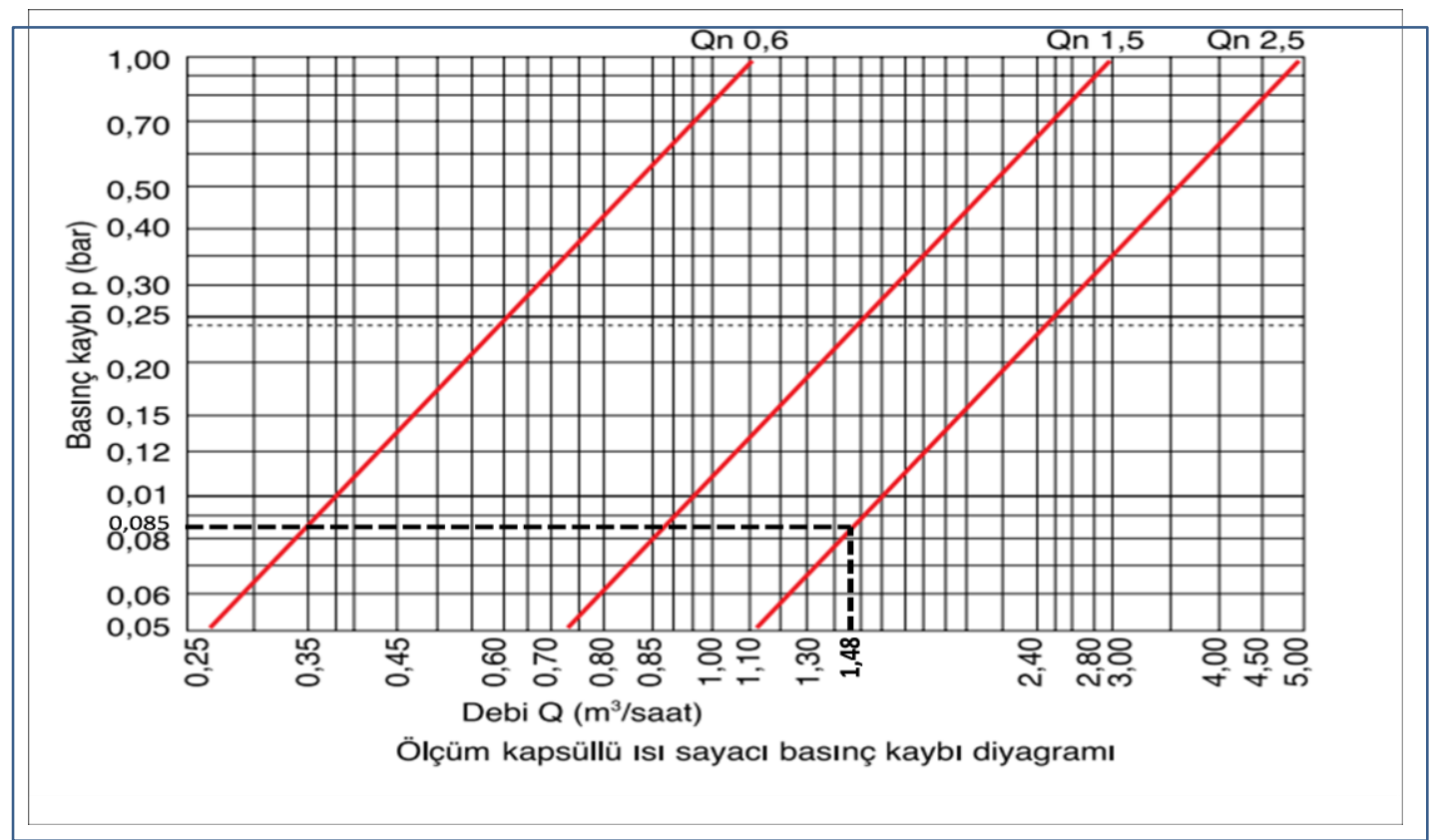

Şekil 4. Isı pay ölçer basınç kaybı grafiği [12] (Plastik ve çelik borular için)

Çizelge 5. Çelik boru için $\zeta$ değerleri

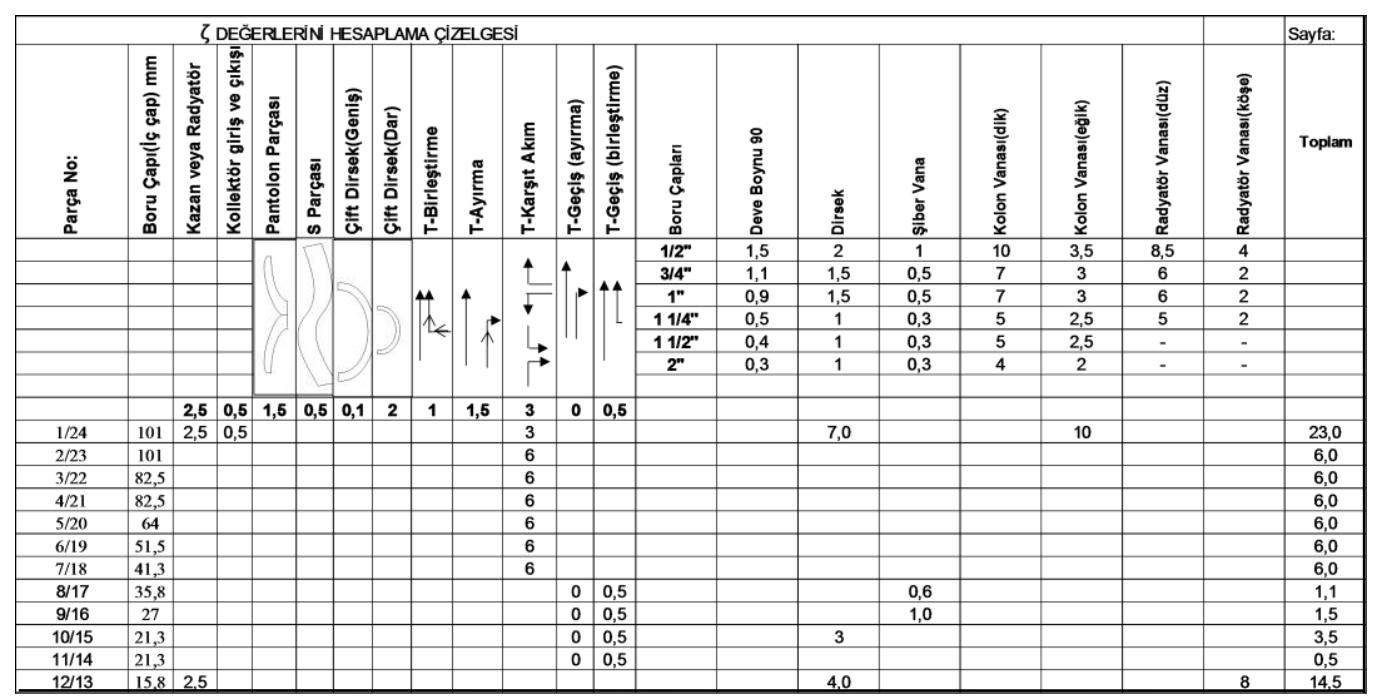


Çizelge 6. Çelik boru için boru hesap cetveli

\begin{tabular}{|c|c|c|c|c|c|c|c|c|c|c|c|c|c|c|c|c|c|}
\hline \multirow[b]{3}{*}{ a } & \multirow[b]{3}{*}{ b } & \multicolumn{6}{|c|}{ Boru Hesabı Cetveli } & & & & & & & & \multirow{2}{*}{\multicolumn{3}{|c|}{$\begin{array}{l}\text { Sahife: } \\
\text { Kat: }\end{array}$}} \\
\hline & & \multirow[b]{2}{*}{ c } & \multirow[b]{2}{*}{ d } & \multirow[b]{2}{*}{$\mathrm{e}$} & \multirow[b]{2}{*}{$f$} & \multirow[b]{2}{*}{$\mathrm{g}$} & \multirow{2}{*}{$\frac{\text {.......Binası }}{\mathrm{h}}$} & \multirow[b]{2}{*}{1} & \multirow[b]{2}{*}{$\mathrm{k}$} & \multirow[b]{2}{*}{$\mathrm{I}$} & \multirow[b]{2}{*}{$\mathrm{m}$} & \multirow[b]{2}{*}{$\mathrm{n}$} & \multirow[b]{2}{*}{0} & \multirow{2}{*}{\multicolumn{2}{|c|}{\begin{tabular}{l|l} 
& $\mathrm{K}$ \\
$\mathrm{p}$ & $\mathrm{q}$
\end{tabular}}} & & \\
\hline & & & & & & & & & & & & & & & & \multicolumn{2}{|c|}{ 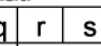 } \\
\hline \multirow{2}{*}{ 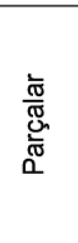 } & \multirow{2}{*}{ 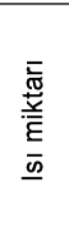 } & \multirow{2}{*}{ 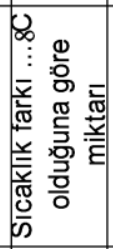 } & \multirow{2}{*}{ 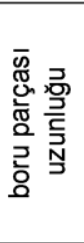 } & \multicolumn{6}{|c|}{ Takribi boru Çapına Göre } & \multicolumn{6}{|c|}{$\begin{array}{l}\text { Değiştirilmiş Boru } \\
\text { Çapına Göre }\end{array}$} & \multicolumn{2}{|c|}{ Fark } \\
\hline & & & & d & $\mathrm{u}$ & $\mathrm{R}$ & LR & $\Sigma \varphi$ & Z & d & W & $R$ & LR & $\mathbf{v}$ & $\varphi$ & LR & Z \\
\hline No & kW & & $\mathbf{m}$ & $\mathrm{mm}$ & $\mathrm{m} / \mathrm{s}$ & $\mathrm{Pa} / \mathrm{m}$ & $\mathbf{P a}$ & & $\mathbf{P a}$ & & $\mathrm{m} / \mathrm{b}$ & $\mathrm{Pa} / \mathrm{m}$ & $\mathbf{P a}$ & & $\mathbf{P a}$ & $\mathbf{P a}$ & $\mathbf{P a}$ \\
\hline $1 / 24$ & 238 & & 10 & 101 & 0,72 & 49,90 & 499,00 & 23 & 5962 & & & & & & & & \\
\hline $2 / 23$ & 204 & & 6 & 101 & 0,62 & 37,80 & 226,80 & 6 & 1153 & & & & & & & & \\
\hline $3 / 22$ & 170 & & 6 & 82,5 & 0,77 & 71,04 & 426,24 & 6 & 1779 & & & & & & & & \\
\hline $4 / 21$ & 136 & & 6 & 82,5 & 0,61 & 46,71 & 280,26 & 6 & 1116 & & & & & & & & \\
\hline $5 / 20$ & 102 & & 6 & 64 & 0,76 & 96,60 & 579,60 & 6 & 1733 & & & & & & & & \\
\hline $6 / 19$ & 68 & & 6 & 51,5 & 0,79 & 133,70 & 802,20 & 6 & 1872 & & & & & & & & \\
\hline $7 / 18$ & 34 & & 6 & 41,3 & 0,62 & 110,50 & 663,00 & 6 & 1153 & & & & & & & & \\
\hline $8 / 17$ & 17 & & 4 & 35,8 & 0,41 & 62,20 & 248,80 & 1,1 & 93,8 & & & & & & & & \\
\hline 9/16 & 9 & & 16 & 27 & 0,37 & 77,40 & $1.238,40$ & 1,5 & 103 & & & & & & & & \\
\hline $10 / 15$ & 7 & & 6 & 21,3 & 0,47 & 159,60 & 957,60 & 3,5 & 387 & & & & & & & & \\
\hline $11 / 14$ & 4 & & 8 & 21,5 & 0,27 & 57,40 & 459,20 & 0,5 & 18,2 & & & & & & & & \\
\hline \multirow[t]{4}{*}{$12 / 13$} & 2 & & 6 & 15,8 & 0,25 & 71,45 & 428,70 & 14,5 & 453 & & & & & & & & \\
\hline & \multicolumn{6}{|c|}{ TOPLAM LR = } & 6809,8 & TOF & $\mathrm{AMZ}=$ & & \multicolumn{3}{|c|}{$15.822,51$} & & & & \\
\hline & & & & & & & & & & & & & & & & & \\
\hline & & & \multicolumn{4}{|c|}{ GENEL TOPLAM = } & \multicolumn{3}{|c|}{$22.632,31$} & & Pa & & & & & & \\
\hline
\end{tabular}

\section{SONUÇ}

$\mathrm{Bu}$ çalışmada 1sıtma tesisatında kullanılan plastik borular için sürtünme basınç kaybı gradyanı (SBKG) çizelgesi $\Delta \mathrm{T}=10^{\circ} \mathrm{C}$ için hesaplanmıştır. Diğer sıcaklık farklarında Eşitlik (12) ye göre sanal bir $\dot{Q}_{S}$ tarif edilerek verilen çizelgeler aynen kullanılabilir. $\mathrm{Bu}$ çizelge kullanılarak örnek bir tesisatta kritik devre boru çapları belirlenmiş ve basınç kayıpları hesaplanmıştır. Hesaplamalar çelik boru için de yapılmıştır. Verilen sonuçlardan görüleceği gibi plastik boru kullanılarak basınç kaybı yaklaşık \%12 oranında azalmaktadır. Bu çalışmada ayrıca sistem analizinde isı pay ölçer de dahil edilmiştir. Maliyet açısından incelendiğinde plastik boru fiyatlarının $30 \mathrm{~mm}$ iç çaplarından sonra, çelik borulara göre arttığı görülmektedir. Ancak işçilik bakımından plastik boruların daha avantajlı olduğu da bilinmektedir.

\section{KAYNAKLAR}

1. 26847 Sayll Resmi Gazete, 2008. Merkezi Isitma ve Sihhi Sicak Su Sistemlerinde Isınma ve Sihhi Sicak Su Giderlerinin Paylaştırılmasına İlişkin Yönetmelik, Bayındırlık ve İskan Bakanlığı, 26847 Sayılı Resmi Gazete, 14.04.2008

2. T. Yilmaz, 2003. Isitma Sistemleri ve Elemanları, ÇÜ MMF yayınları, Adana,

3. TMMO, 2012. Kalorifer Tesisat1, MMO Yayınlar1/352/7 
Isıtma Tesisatında Kullanılan Plastik Borular için Sürtünme Basınç Kaybı Gradyanı Çizelgesinin Hazırlanması ve Örnek Projeye Uygulanması

4. Isısan Çalışmaları, 2000. Borular, Vanalar, Pompa ve Boru Çapı Hesabı, Isıtma Tesisatı, Böl:7.

5. A.Akar,www.mmo.org.tr/resimler/dosya_ekl er/60320be12a1c050_ek.pdf?dergi=149, erișim tarihi: 29.04 .2015

6. İ. Çakmanus, H. İman, 2000. Mekanik Tesisat Sistemlerinde Kullanılan Borular, TTMD Dergisi, Sayı:10.

7. ASHRAE HVAC Systems and Equipment Handbook, Pipes, Tubes and Fittings, Part 41, 2004.

8. H. Bulgurcu, G. Özmen, 2011. Yaygın Olarak Kullanılan Bazı Sihhi Tesisat Elemanlarındaki Basınç Kayıplarının Kuramsal ve Deneysel Olarak Hesaplamas1, X. Ulusal Tesisat Kongresi, İzmir, 19731992.

9. M. H. Zgoul, S. M. Habali, 2008. An Investigation Into Plastic Pipes as Hot Water Transporters in Domestic and Industrial Applications" Jordan Journal of Mechanical and Industrial Engineering, Vol.2, No:4, 191-200.

10. ASHRAE Handbook-Fundamentals, 2009. Pipe Sizing, Chapter 22.

11. C.F. Colebrook, 1939. Turbulent Flow in Pipes, with Particular Reference to the Transition Between the Smooth and Rough Pipe Laws, Journal of the Institute of Civil Engineers London, 11, 133-156.

12. Techem 1S1 sayaçları, 2015. www.techem.com.tr (Erișim tarihi: 16.06.2015). 